\title{
Fatty acids: facts vs. fiction
}

\author{
Reinhard Waehler (1)
}

TISSO Naturprodukte GmbH, Wenden, Germany

\begin{abstract}
During the last 100 years official dietary guidelines have recommended an increased consumption of fats derived from seeds while decreasing the consumption of traditional fats, especially saturated fats. These recommendations are being challenged by recent studies. Furthermore, the increased use of refining processes in fat production had deleterious health effects. Today, the number of high-quality studies on fatty acids is large enough to make useful recommendations on clinical application and everyday practice. Saturated fats have many beneficial functions and palmitic acid appears to be problematic only when it is synthesized due to excess fructose consumption. Trans fatty acids were shown to be harmful when they are manmade but beneficial when of natural origin. Conjugated linoleic acid has many benefits but the isomer mix that is available in supplement form differs from its natural origin and may better be avoided. The $\omega 3$ fatty acid linolenic acid has rather limited use as an anti-inflammatory agent - a fact that is frequently overlooked. On the other hand, the targeted use of long chain $\omega 3$ fatty acids based on blood analysis has great potential to supplement or even be an alternative to various pharmacological therapies. At the same time $\omega 6$ fatty acids like linoleic acid and arachidonic acid have important physiological functions and should not be avoided but their consumption needs to be balanced with long chain $\omega 3$ fatty acids. The quality and quantity of these fats together with appropriate antioxidative protection are critical for their positive health effects.
\end{abstract}

Keywords: saturated fatty acids, trans fatty acids and conjugated linoleic acid, $\omega 7$ fatty acids, $\omega 3$ and $\omega 6$ fatty acids, omega- 3 index, statins, fish oil quality and dosage

\section{Introduction}

Despite decades of research, public perception of fats is still a mixed bag. Health experts are giving conflicting advice to patients and consumers [1]. The latter is then left to his or her own devices [2]. Some areas that can be confusing are the differentiation between short and long chain $\omega 3$ and $\omega 6$ fats, between natural and manmade trans fats and the actual dangers of saturated fats.

Observational studies and correlations are still the basis for many nutritional recommendations. However, these studies are frequently of limited value [3] if they are not at least combined with biochemical mechanisms for adequate interpretation. Furthermore, many nutritional studies use questionnaires without taking blood samples or biopsies. This approach is highly inadequate given that people's memories of their eating habits rarely cover weeks, months or even longer periods and self-reporting is inherently flawed $[4,5]$. In addition, there are further issues with nutrition research. As discussed below, the influence of major industries, e.g. seed oil and sugar industry, on scientific publications together with marketing campaigns and their influence on medical associations can heavily mould public perception and official recommendations of nutrients, sometimes leading to unhealthy habits [6-8].

While not the subject of this review, viewing nutrition from an evolutionary perspective also helps to gain a realistic perspective. Our genetics have remained virtually unchanged over the last 10,000 years, our diet, however, has changed significantly in the last 120 years [9]. The increase in total fat consumption began around 1800 but the most notable changes occurred since 1900. Those are characterized by a massive increase in trans fatty acid and $\omega 6$ fatty acid consumption and a decrease in $\omega 3$ fatty acids. Antioxidants like vitamins $\mathrm{E}$ and $\mathrm{C}$ in our foods have decreased simultaneously [10]. These key areas for achieving better health are also interrelated. Trans fatty acids block the conversion of the short chain $\omega 3$ and $\omega 6$ fats to their critically important long chain derivatives [11]. All polyunsaturated fats are prone to oxidation that renders them useless or even harmful if the diet contains insufficient antioxidants [12]. Deviations from an evolutionary diet are not inevitably harmful but a concomitant increase in chronic diseases for both young and older individuals in developed nations [13] warrants a closer look at the key nutrients for which quantities and qualities have changed. While people are living longer in industrialized nations, their healthy life span is not increasing $[14,15]$.

\section{Saturated fats: benefit or harm?}

Saturated fats were demonised for many decades: the cover of TIME magazine in 1961 damning them and ushering in the "low-fat" era epitomised the dominant narrative [16]. The scientific facts, however, suggest rather the opposite, or require more sophisticated consideration at the very least [17-20]. 


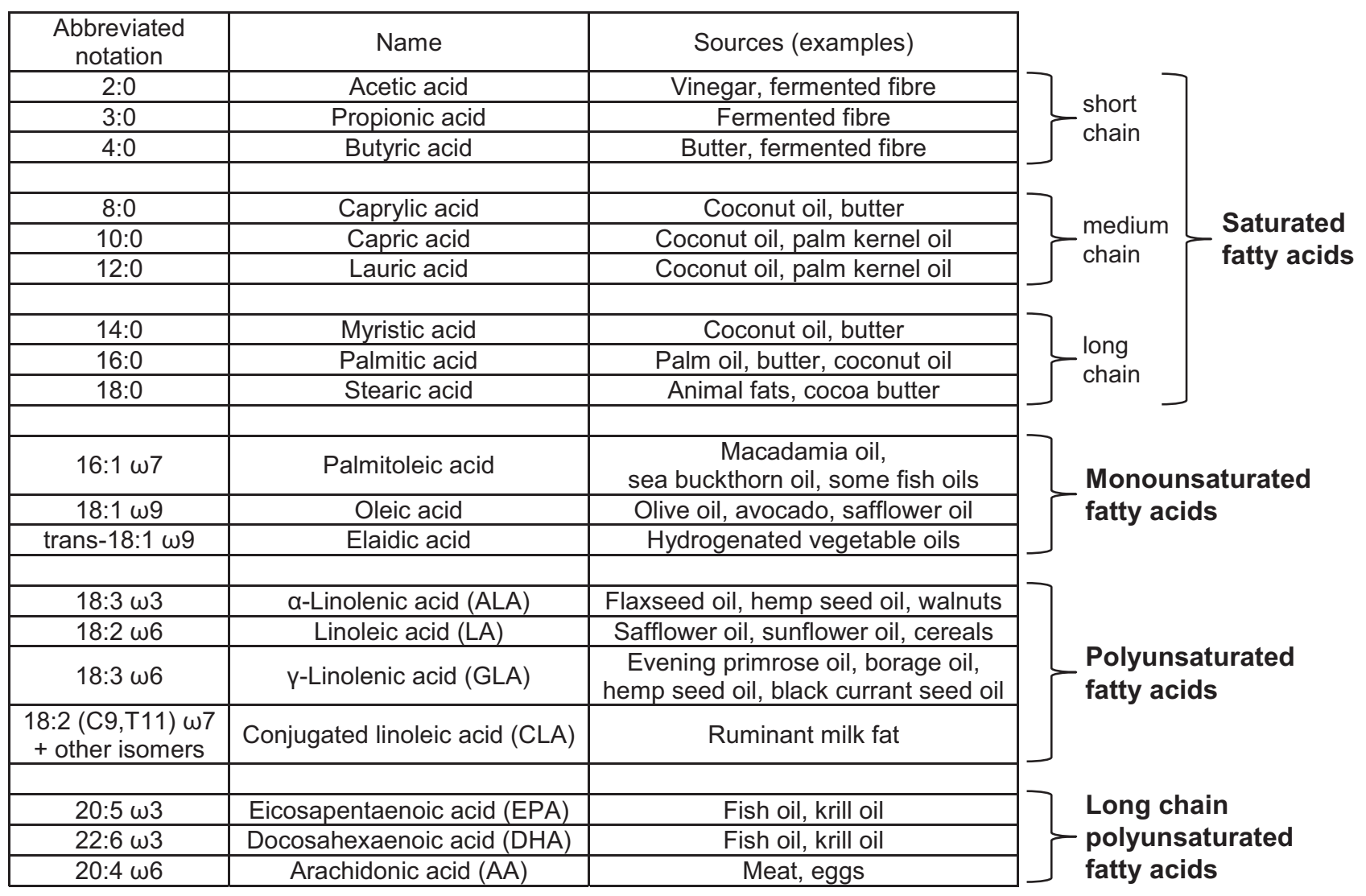

Figure 1. Overview of important fatty acids discussed in the text [45, 114, 237-242].

Chemically speaking, fatty acids are hydrocarbon chains with a carboxyl group at one end (Figure 2). The latter (carboxylic acid) is the reason why they are called acids. Saturated means that all the carbon atoms are connected to the maximum number of hydrogen atoms and thus there are no double bonds in the hydrocarbon chain [21]. Examples of saturated fats are shown in Figure 1. On the face of it, saturated fats differ only in the length of their hydrocarbon chains.

Saturated fats were long considered harmful until only relatively recently, largely due to the interpretation of studies by Ancel Keys. A study of his from 1953 purports to show - based on data from only six selected countries - that increased fat consumption is associated with a higher death rate [22]. A later study covering 22 countries demonstrated a much weaker correlation of this assumed connection [23]. The now highly controversial "Seven Country Study" published in 1970, 1980 and 1984 appeared to establish a correlation between saturated fats and cardiovascular disease [24]. However, correlations are often random and do not indicate causation [25]. Nevertheless, in the wake of these publications, nutritional guidelines of most countries across the world recommended limiting the consumption of saturated fats in favour of unsaturated fats and carbohydrates [26, 27]. Controlled clinical and epidemiological studies have not, on closer analysis, given any grounds for the official nutritional recommendations to replace saturated fat with carbohydrates. Clinical studies show that mortality overall and due to cardiovascular events does not decrease as a result of reduced saturated fat consumption $[26,28,29]$. At no point in time was there a rational basis for limiting the consumption of natural dietary fats, or specifically the consumption of saturated fats [30]. Moreover, such restrictions of saturated fats can be accompanied by increased consumption of $\omega 6$ fats, trans fats and carbohydrates as substitutes. It can be speculated that these recommendations were driven by vested political and economic interests. Unfortunately, they caused great damage to the health of entire populations [30-32].

The influence of the sugar industry, including on scientific publications, aimed at vilifying fats and cholesterol in connection with heart disease and whitewashing sugar, is now well documented $[33,34]$. The interests of the oil and sugar industries seem to have overlapped insofar as both were able to benefit from reduced consumption of traditional saturated fats, such as animal fats. 
(A) Saturated fatty acid (Caprylic acid)

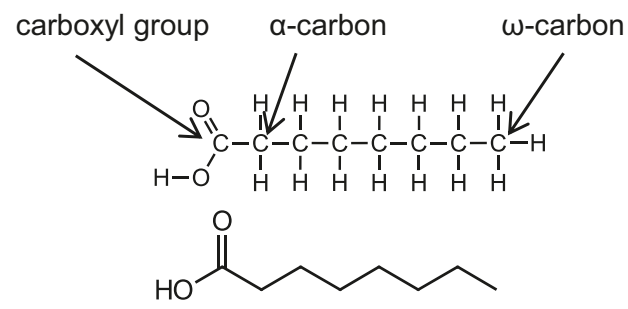

(B) Trans fatty acid (Elaidic acid)

- Man-made<smiles>CCCCCCCCC/C=C/CCCCCCCC(=O)O</smiles>

- Melting point $47^{\circ} \mathrm{C}$

- Trans isomer of oleic acid

(C) Cis fatty acid (Oleic acid)<smiles>CCCCCCCCC/C=C\CCCCCCCCC(=O)O</smiles>

(D) Polyunsaturated fatty acids

carbon atoms double bonds 1st double bond

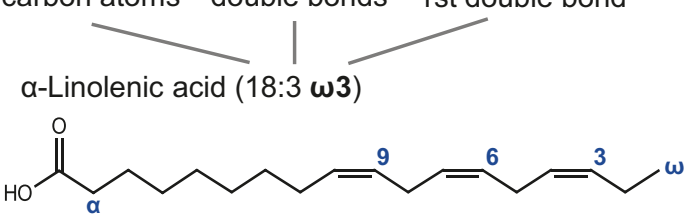

Linoleic acid (18:2 $\omega 6)$<smiles>CCCCCC=CCC=CCCCCCCCC(=O)O</smiles>

Figure 2. Structures of exemplary fatty acids: A) saturated fatty acids, B) trans fatty acid and C) its natural counterpart [21, 243], D) essential fatty acids.

\section{How sugar leads to harmful fat production}

The high consumption of sugar and particularly fructose has now emerged as a much more realistic cause of the obesity epidemic and the closely associated metabolic syndrome. This realisation is based not just on epidemiological but also biochemical data $[35,36]$. Of particular concern is the consumption of large quantities of concentrated fructose within a short time, e.g. in the form of fruit juice or lemonade. The cells of the small intestine can only convert a small amount of fructose (approx. $3 \mathrm{~g}$ at a time) into metabolically harmless metabolites (e.g. glucose, lactate and glycerate). When higher amounts are ingested, the cells of the small intestine are no longer able to convert all the incoming fructose into these harmless metabolites. Instead, the fructose is channelled to the liver and stored as excess energy in the form of palmitic acid [37]. The consequences of long-term overconsumption of fructose are fatty liver and metabolic syndrome (Figure 3) [37, 38].

\section{Not all saturated fats are the same}

Independent of these consequences of high fructose consumption, it should be noted that the effects of different saturated fats on the human organism are highly variable. 
Fructose $\uparrow$ (Carbohydrates $\uparrow$ )<smiles>C[Al]</smiles>

De-novo lipogenesis $\uparrow$<smiles>CCCCCCCCCCCCCCCC(=O)O</smiles><smiles>C1CC1</smiles>

Palmitic acid $\uparrow$<smiles>[CH]1CCC1</smiles>

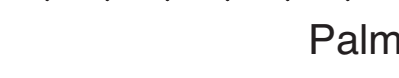

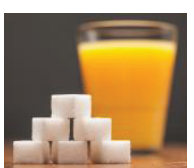

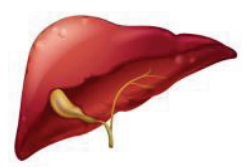

$\mathrm{HO}$

Palmitic acid binds Toll-like receptor 4 (TLR4) on macrophages, astrocytes, cardiomyocytes

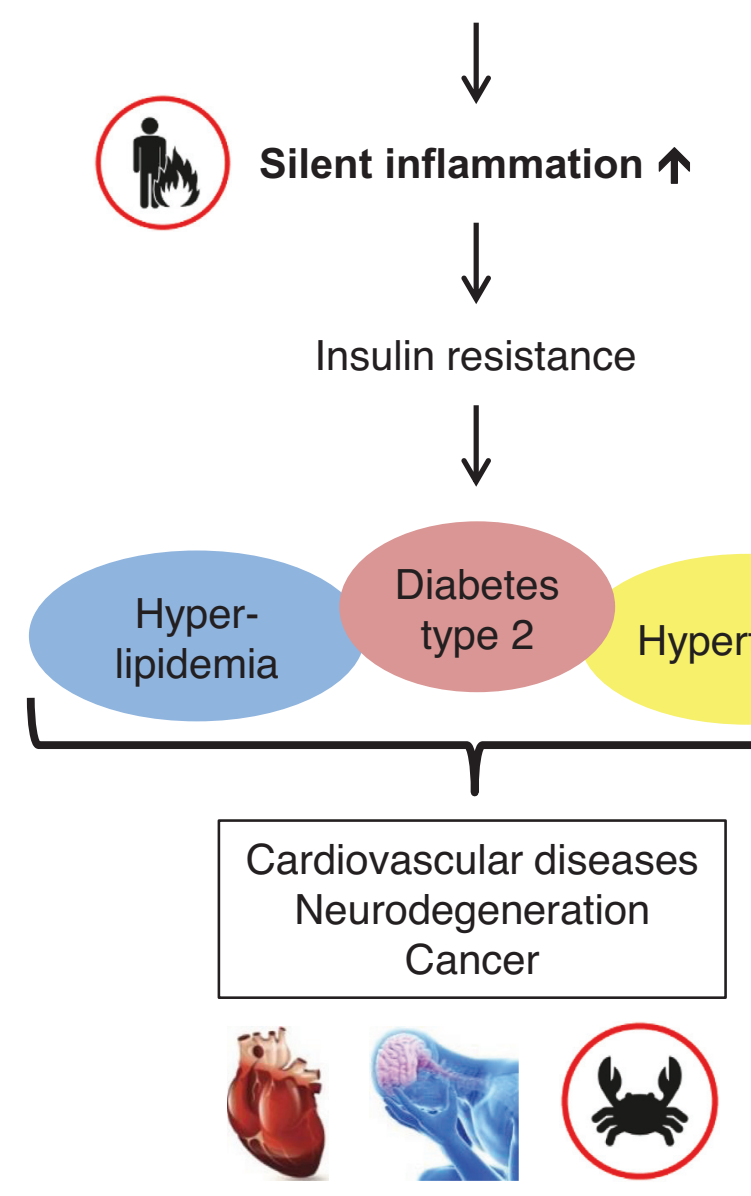

Oxidative stress $\uparrow$

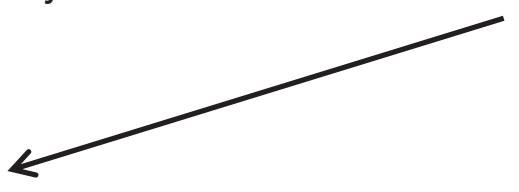

$\downarrow$

Mitochondrial fragmentation

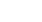


To generalize the health effects of these fats - especially extrapolating from palmitic acid to other fats - is scientifically unacceptable, but unfortunately still a widespread simplification [39]. The following examples clearly demonstrate this.

For instance, the short-chain saturated fatty acid butyric acid is actually extremely beneficial to health. This fatty acid can be supplied via milk fat (3-4\% butyric acid), but is mainly formed by the microbiota in the large intestine through the fermentation of soluble fibre. Butyric acid has anti-inflammatory and cancer-preventive effects and improves mitochondrial function as well as insulin sensitivity [40, 41].

Medium-chain fats, found especially in coconut oil, have a variety of benefits. Caprylic, capric and lauric acids have antibacterial, antiviral and anti-candida properties. Lauric acid has even been found to be effective against Helicobacter pylori, caries and plaque [42]. Caprylic and capric acid have also shown potential in the treatment of cognitive impairment and Alzheimer's [43, 44]. In patients with coronary heart disease, the addition of $13 \mathrm{ml}$ coconut oil (48\% lauric acid, 19\% myristic acid, 9\% palmitic acid) per day was able to significantly improve clinically relevant markers (including HDL cholesterol) compared to the control group (no added coconut oil) [45].

Among the long-chain saturated fatty acids, palmitic acid is of particular interest. It is unique among the saturated fats because it plays an essential role in numerous pathological processes as an intracellular signal molecule. Metabolic syndrome, cardiovascular disease, cancer, neurodegenerative diseases and inflammation are worth mentioning in this context, where palmitic acid functions as a molecular signal transmitter [46]. A person weighing $70 \mathrm{~kg}$ contains of $3.5 \mathrm{~kg}$ of palmitic acid on average. Changes in the consumption of this fatty acid do not significantly affect tissue concentrations under physiological conditions, as these are compensated by endogenous de novo lipogenesis. This homeostatic control can be attributed to the importance of palmitic acid for the physical properties of cell membranes [47]. Furthermore, so-called palmitoylation plays an important role. This modification of proteins by palmitic acid anchors them in the cell membrane. Palmitic acid is also central to the biosynthesis of palmitoylethanolamide (PEA), an endogenous pain reliever and anti-inflammatory [47].

The overconsumption of carbohydrates that can no longer be stored as glycogen and are not needed for energy production, especially the excessive consumption of fructose as pointed out above, leads to increased de novo lipogenesis of palmitic acid (Figure 3). Nevertheless, it would be short-sighted to see palmitic acid as a culprit. Current evidence indicates that health problems are not caused by palmitic acid ingested with food, but by palmitic acid produced in our cells due to the dietarily induced de novo lipogenesis $[38,48]$.
Additionally, the different fatty acids ingested with food interact with each other and with those already present in the body. For example, cell culture experiments have shown that addition of the monounsaturated fatty acid oleic acid can cancel out the negative effects of isolated palmitic acid [39].

Also, the inflammatory reaction triggered by palmitic acid and mediated by TLR4 (Toll-like receptor 4) can be blocked at the cell membrane [49] and intracellularly [50] if the long-chain $\omega 3$ fatty acids EPA/DHA are supplied. As a therapeutic recommendation, it can be concluded that some of the negative effects of fructose overconsumption leading to de novo lipogenesis of palmitic acid can be alleviated by EPA/DHA. At the same time the consumption of fructose, especially if highly concentrated, should be reduced.

The fatty acid next in line after palmitic acid is stearic acid. This fatty acid is very different to isolated palmitic acid. Stearic acid does not cause the development of insulin resistance or diabetes [51], has favourable effects on cholesterol and blood coagulation $[52,53]$ and may even have antitumour effects [54].

\section{Saturated fats do not cause cardiovascular disease}

Statistical data for 41 European countries show that increased consumption of saturated fats is associated with considerably less heart disease [55]. This association does not mean that saturated fats prevent heart disease. However, it could mean that the increased consumption of saturated fats, if accompanied by lower consumption of fructose or trans fats, has a positive effect on health.

More than 25 studies have shown that patients with coronary heart disease do not eat more saturated fats than people without this disease. In seven studies, stroke patients had actually consumed significantly less of these fats. The data appear to be clear: the consumption of saturated fats is not responsible for cardiovascular disease $[56,57]$.

\section{Actual causes of cardiovascular disease}

Some scientific publications now acknowledge that saturated fats do not clog the arteries [58, 59]. Instead, coronary heart disease is acknowledged to be due to silent inflammation. The causes of the latter are identified as insufficient consumption of $\omega 3$ fats, overconsumption of $\omega 6$ fats and excessive consumption of fructose and refined carbohydrates [60]. The consumption of vegetables, virgin olive oil, fatty fish, nuts, the moderate consumption of cheese/ yoghurt and low consumption of sugar and refined carbohydrates have a protective effect. These foods provide the 
organism with $\omega 3$ fats, polyphenols and fibre. In terms of lifestyle, regular physical activity, stress reduction (e.g. meditation, yoga) and giving up tobacco consumption are recommended [60]. Saturated fats are an essential component of a healthy diet [59].

Far more relevant than the fat content of the food is its level of processing. Excessively processed food is a causal factor for weight gain because it leads to a substantially greater consumption of calories. Differences in protein consumption and eating rate may explain the increase in calorie consumption to some degree [61]. Further factors are likely to play a role and require additional studies to evaluate their contributions. The route to good health appears to be to eat natural and freshly prepared food.

\section{Toxic manmade vs. healthy natural trans fats}

Trans fatty acids are stereoisomers of natural cis fatty acids. Chemically, they differ only in their geometry from their natural variant (Figures $2 \mathrm{~b}$ and $2 \mathrm{c}$ ). While trans fatty acids have a linear configuration, cis fatty acids have a kink due to the repulsion of hydrogen atoms on the same side of the double bond [62]. Mammals and most edible plants produce only cis fatty acids [63]. The natural trans fatty acids that are formed by bacterial fermentation in the rumen of ruminants are an exception to this [64].

\section{Manmade trans fats}

The widespread use of man-made or industrial trans fatty acids (hereinafter referred to as trans fats) began in the $20^{\text {th }}$ century. In 1909, the consumer goods company Procter \& Gamble commercialised a partially hardened vegetable oil with a long shelf life called Crisco ${ }^{\circledR}$ (crystallised cottonseed oil) [65]. It was initially obtained from a waste product of cotton production, the cotton seed. Later soybeans became the raw material. Due to the partial hardening of the fats, about half of it consisted of trans fats [66]. In 1948, a donation of approx. USD 1.5 million (roughly USD 12-29 million today [67]) from Procter \& Gamble to the American Heart Association (AHA) ensured that this previously insignificant organisation gained enormous influence $[68,69]$. For decades, the AHA recommended reducing the consumption of saturated fats in favour of oils rich in trans and $\omega 6$ fats, without a sufficient scientific basis [70].

Trans fats have been widely used over the last 100 years, especially in processed foods, to replace the saturated or animal fats that were considered unhealthy at the time. These unnatural trans fats are cheaper than animal fats with similar physical but different biological properties. These advantages in their industrial use have been acquired at the price of considerable health hazards [71], especially with increasing cardiovascular as well as neurological disease $[72,73]$.

The structural difference between trans fats (e.g. elaidic acid) and their natural cis isomers (e.g. oleic acid) explains at least some of the pathological effects of trans fats. After consumption, fatty acids are incorporated into cell membranes. The linear structure of trans fats enables stronger interactions between the fatty acids and increases cholesterol in the cell membrane. The former is key in causing the membrane to become more rigid [74]. The activation of membrane-bound receptors is generally accompanied by a change in their conformation. A more rigid cell membrane due to increased trans fat content makes this conformational change more difficult and thus reduces receptor activation. This has been proven experimentally [74]. This alone can already explain some of the negative effects of trans fats. When compared with structurally similar saturated fatty acids it appears plausible that the regulation of the membrane content of specific fatty acids like palmitic acid [47] cannot apply to industrial trans fatty acids. The mechanisms of how trans fats cause disease is still the subject of research [75]. There is evidence that they affect the function of cyclooxygenases, in particular COX-2, and prevent the formation of long-chain $\omega 6$ and $\omega 3$ fats and the synthesis of prostacyclin [72, 76, 77]. Prostacyclin (PGI2) is needed to prevent pathological blood clots. Such clots in the coronary arteries can otherwise lead to sudden death [76]. Generally, prostacyclin inhibits platelet aggregation, is vasodilatory and thus necessary for physiological blood circulation. A trans fat induced prostacyclin deficiency therefore contributes significantly to heart disease [77]. The negative influence of trans fats on the synthesis of EPA/DHA is described below. Pastries and sugary foods often contain high amounts of industrial trans fats [78]. In the EU, there are no formal restrictions on trans fats in food. However, efforts are underway to limit their content to a maximum of $2 \%$ of the fat contained in food [79]. In the USA, manufacturers have not been allowed to add trans fats to food since 2018 [80]. A meta-analysis of numerous human studies has shown that trans fats - in contrast to saturated fats - increase overall mortality [81, 82].

\section{Natural trans fats}

With trans fats, the adverse health effects are clearly evident in industrial trans fats (especially elaidic acid), while no disadvantages were found for trans fats from ruminants (especially vaccenic acid) [81, 82]. The most important natural sources of trans fats are milk fat and meat from grassfed ruminants [83, 84]. In these animals, bacteria are responsible for the production of natural trans fats. Butter contains approx. $3-4 \%$ of natural trans fats [78]. 
A study with more than 3,600 participants has shown that the increased consumption of milk fat from grass-fed cows leads to fewer heart attacks. In particular, conjugated linoleic acids (CLA), as natural trans fatty acids, appear to be protective. Participants with the highest CLA content in their adipose tissue cut their risk of heart attack in half compared to those with the lowest CLA content (a statistically highly significant trend). Increased consumption of milk fat appears to improve heart health, provided that cows eat grass [85]. Other studies paint an equally positive picture. The higher consumption of milk fat is again associated with reduced cardiovascular mortality [86-88]. A further explanation for the positive influence of natural trans fats may be the conversion of vaccenic acid to CLA, which also takes place in humans [89].

CLA from butter consist of approx. 12 different CLA isomers, of which about $80 \%$ are rumenic acid (cis-9,trans-11) $[90,91]$. However, CLA in the form of food supplements consists of only $50 \%$ rumenic acid and $50 \%$ trans- 10 , cis-12 isomer, which is not present in butter [91]. Clinical studies showed the latter to have negative effects on health, although these were cancelled out by the rumenic acid [92]. Unfortunately, an isolated test of rumenic acid was not carried out. In view of the studies with CLA-containing milk fat, however, it can be assumed that rumenic acid is responsible for the positive effects. The implication is that CLA-containing butter can be recommended, while the CLA-isomer mixture contained in supplements, which is artificially produced (usually from safflower oil), is largely useless or even harmful, at least in humans [93].

From the above studies one can conclude that while industrial trans fats are highly problematic for health, natural trans fats together with the saturated fats contained in milk fat can be beneficial.

\section{$\omega 7$ - positive effects of a lesser known monounsaturated fatty acid}

The best-known representative of monounsaturated fatty acids is oleic acid (18:1 $\omega 9)$, which is found in olive oil, amongst others. Numerous positive health effects have long been known for this fatty acid [94].

cis-palmitoleic acid (16:1 $\omega 7)$ is a less well-known monounsaturated fatty acid. It is mainly found in macadamia oil, sea buckthorn oil and some fish oils. Preclinical studies have shown that this fatty acid improves insulin sensitivity, reduces inflammation [95] and has beneficial effects on the cardiovascular system [96]. It can therefore be a very useful addition to EPA/DHA, as it supports their benefits via other metabolic pathways [97]. In a clinical study, $220 \mathrm{mg}$ of cis-palmitoleic acid per day has proven sufficient to curb inflammation and lower blood lipids [98]. Another study showed a reduction of inflammatory markers in patients with ulcerative colitis [99].

\section{$\omega 3$ and $\omega 6$ essential fatty acids: the importance of chain length for biological activity}

The shortest representatives of the essential fats are found in vegetable seeds and their oils: $\alpha$-linolenic acid (ALA) is an $\omega 3$-fatty acid, as found in flax or hemp seeds (Figure 1). The shortest representative of the $\omega 6$ fatty acids is linoleic acid (LA). The significance of these two essential fatty acids is mainly due to the fact that humans can produce the physiologically important fatty acids arachidonic acid (AA), eicosapentaenoic acid (EPA) and docosahexaenoic acid (DHA) from them (Figure 4). However, the synthesis of AA, EPA and DHA does not usually occur in sufficient quantities, which is why these are sometimes also considered essential or at least semi-essential [100,101].

The body needs AA, EPA and DHA to both initiate and terminate inflammation (Figure 4). Inflammation is vital for a physiological immune response. $\omega 6$ fatty acids per se are not harmful at all. Various clinical studies have shown that supplementation with LA does not increase inflammation markers in healthy volunteers [102]. For people suffering from high oxidative stress, however, an increase in LA consumption at the expense of saturated fats can increase cardiovascular risk. LA is also problematic if it is derived from industrially produced vegetable oils where the oil has been at least partially oxidized due to processing [103].

In particular, the $\omega 6$ fatty acid AA is vital for immune response, wound healing [104] muscle repair and growth after exercise [105], as well as indirectly for the aforementioned inhibition of thrombocyte aggregation by prostacyclin. In healthy volunteers, dietary supplementation with AA (in clinical studies up to $1500 \mathrm{mg}$ /day) does not lead to adverse effects on the inflammatory process or overall health. It is unclear whether there are health benefits to be gained from the additional intake of AA above the range of 100-200 $\mathrm{mg} /$ day usually provided by the diet. At least cognitive benefits in old age and increases in strength and muscle mass in young adults who exercise have been observed [106].

Sufficient amounts of AA, EPA and DHA are required for a balanced inflammatory process. They do not trigger these processes themselves, but rather the lipid mediators for the inflammatory process produced from them. More important than the absolute amounts of these fatty acids is the ratio in which they are consumed [107]. This topic will be further discussed in connection with the omega-3 index below. 


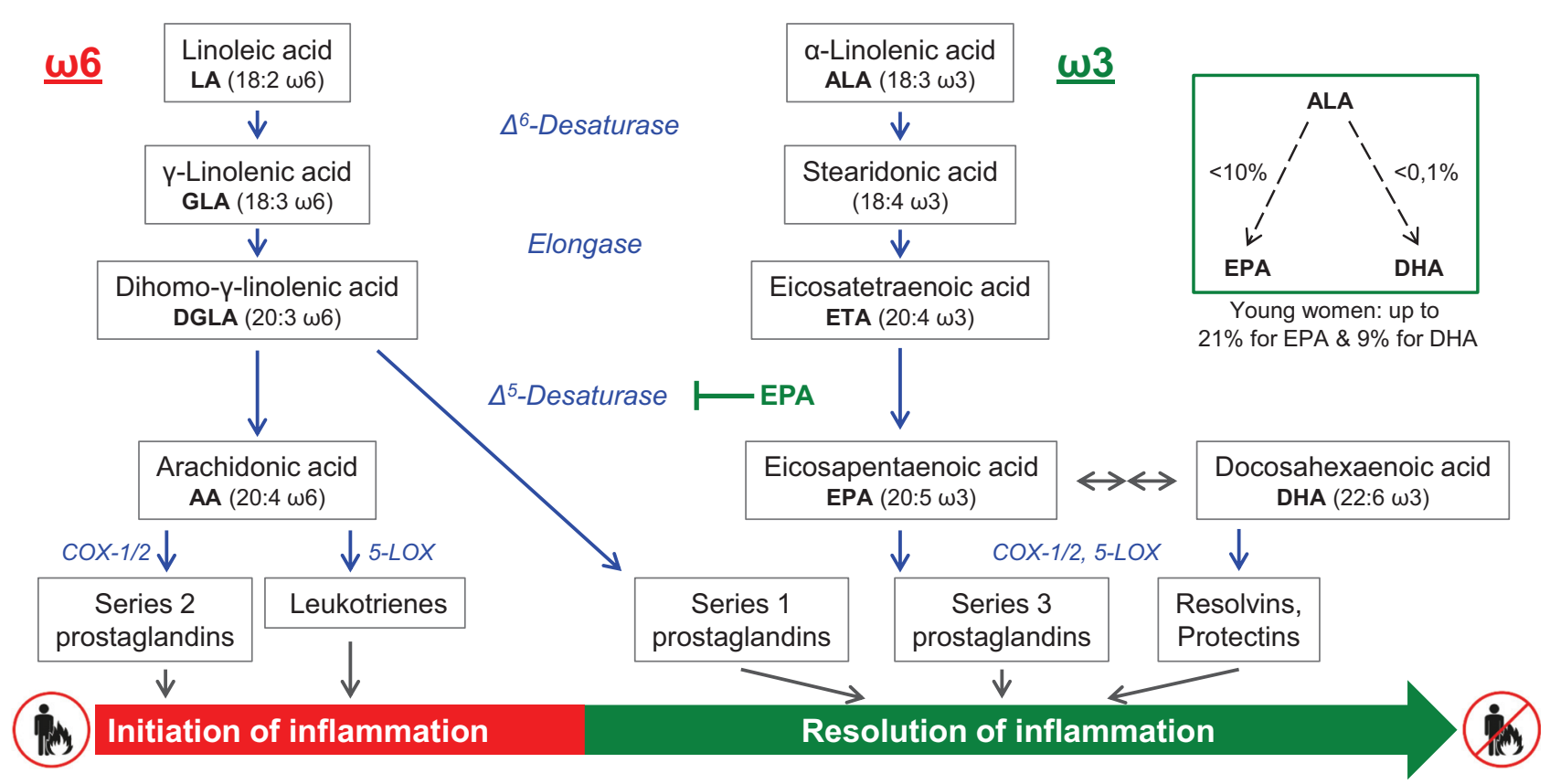

Figure 4. Fatty acids and inflammation [125, 253-255]. ALA: $\alpha$-Linolenic acid, EPA: Eicosapentaenoic acid, DHA: Docosahexaenoic acid, COX-1/2: Cyclooxygenase-1 and -2, 5-LOX: 5-lipoxygenase

\section{Conversion of short to long chain $\omega 3$ and $\omega 6$ fatty acids is inefficient}

The conversion of linoleic and $\alpha$-linolenic acid to the physiologically essential long-chain fatty acids takes place in several steps (Figure 4). The same enzymes metabolise LA, ALA and oleic acid ( $\omega 9): \Delta^{6}$ - and $\Delta^{5}$-desaturase. These fatty acids therefore compete for those enzymes, with the enzymes showing the greatest preference for $\omega 3$, followed by $\omega 6$ and then $\omega 9$ (not in Figure 4 ). The activity of $\Delta^{5}$ desaturase is limited in humans [108], which explains why the conversion of dihomo- $\gamma$-linolenic acid (DGLA) to AA, but also of eicosatetraenoic acid (ETA) to EPA, is rather inefficient. EPA prevents the conversion of DGLA to AA [109], as it inhibits the activity of $\Delta^{5}$ desaturase [110]. In contrast, insulin increases the activity of desaturases and can promote this conversion [111]. To achieve the best possible conversion of DGLA to the anti-inflammatory series 1 prostaglandins [112], the administration of EPA or fish oil appears to be a sensible addition to substitution with GLA (e.g. from evening primrose oil [108]) while simultaneously reducing carbohydrate consumption.

The low activity of desaturases can lead to insufficient conversion to the long-chain $\omega 3$ and $\omega 6$ fatty acids. This, in turn, can make supplementation with GLA, EPA, DHA and in rare cases even AA necessary, unless these long-chain polyunsaturated fatty acids (AA, EPA, DHA) are provided by (grassfed) beef, fish and eggs. The conversion from LA to AA is less than $0.5 \%$ for men $[107,113]$. Even if there are no data regarding this conversion for women of childbearing age, it is likely that, by analogy with the higher conversion rate of ALA to EPA/DHA, this conversion is also significantly higher than for men (see discussion on flax seed oil below). The synthesis of the fatty acid DHA from ALA, which is crucial for eyes and brain, is particularly low. A protein-rich diet $(\geq 35 \%)$ increases the activity of $\Delta^{6}$ desaturase, mainly in old age $[114,115]$. In general, the activity of desaturases decreases with age. Numerous studies demonstrate a protective effect of EPA and DHA, especially, against cancer and cardiovascular disease. The decline in these enzyme activities appears to be a very likely and important co-factor for the increase of these diseases with age [114]. The necessity of supplementing the diet with fish oil for preventive as well as curative purposes in various age-related diseases becomes apparent against this backdrop. Trans fatty acids inhibit both desaturases $[116,117]$ and thus lead to reduced synthesis of the inflammation-dissolving long-chain $\omega 3$ fats. This effect alone is probably responsible for at least a portion of the known pro-inflammatory effects of trans fats and their associated diseases [118-120].

A number of micronutrients are involved in the synthesis of the long-chain $\omega 3$ and $\omega 6$ fatty acids from LA and ALA [114]: Zinc is one, which may explain its benefits for inflammatory skin diseases, for instance [121, 122]. Magnesium [123] and vitamin C support the action of $\Delta^{6}$ desaturase [124]. Calcium, selenium and the vitamins niacin and B6 are also involved in the fatty acid metabolism described here $[125,126]$. 


\section{Is flaxseed oil a useful source of $\omega 3$-fats?}

Patients often ask if they can cover their $\omega 3$ needs with flaxseed oil. The efficiency of converting ALA to EPA/DHA depends on several factors. Gender, diet and age all play a role. Studies have shown a conversion of ALA to EPA in the range of $0.2 \%$ [127] to $8 \%$ [128], and up to $21 \%$ in young women [129]. The conversion of ALA to DHA is typically $<0.1 \%$ [130, 131], with one study reporting 4\% [130]. Up to $9 \%$ has been observed in young women [129]. The ability of young women to better convert ALA to EPA/DHA may have hormonal causes, and is undoubtedly of great physiological relevance during pregnancy and lactation $[132,133]$.

A recent study on 19 men (average age 26) confirmed the mostly insufficient conversion of ALA to EPA and especially DHA. The test persons received $13 \mathrm{~g}$ of ALA daily for 12 weeks. As expected, EPA concentration increased while DHA surprisingly decreased. The sum of EPA plus DHA concentration (measured in erythrocytes), which is crucial for the benefits of $\omega 3$ fats, did not change [134]. This underlines that ALA and thus flaxseed oil is generally not a good source for generating sufficient EPA/DHA. If the intake of LA is greatly reduced and the consumption of ALA is significantly increased (LA/ALA ratio 0.56:1), erythrocyte EPA levels may rise slightly. This however has no effect on DHA levels [135]. Moreover, such extreme regimes are unrealistic for most people in the long run.

The deciding factor is therefore not just to what degree $\omega 3$ and $\omega 6$ fatty acids are ingested, but also the amount that can be converted to long-chain $\omega 3$ fatty acids. If the conversion of short-chain $\omega 3$ fatty acids to EPA/DHA is insufficient, the intake of the latter, e.g. through consumption of fish or fish oil, is advisable.

The same limitations apply to the conversion of LA to AA, but AA is usually present in sufficient levels in the western diet, provided the diet is omnivorous $[107,136]$. On the other hand, EPA/DHA measurements in about 3/4 of test persons showed suboptimal levels [137]. Thus, supplementation is frequently appropriate since insufficient levels of these fatty acids are often found in a typical Western diet, especially if fish is avoided [138].

\section{Effects of fatty acids on the cell membrane}

Saturated fats [139], trans fats [140] and cholesterol [141] make the cell membrane more rigid, while unsaturated fats make it more fluid [142]. For a functioning membrane all fats must be in their physiological balance, except for artificial trans fats, which should be absent. The fluidity of the membrane thus generated has a decisive influence on the number of receptors and their affinity to their hormones, growth factors and proteins [143-145]. A rigid cell membrane has fewer insulin receptors, for example, and their affinity for insulin is also reduced. This may contribute considerably to insulin resistance [146]. In contrast, unsaturated fats lead to higher membrane fluidity, lower cholesterol and a higher number of insulin receptors with increased affinity for insulin. This leads to a reduction in insulin resistance [146, 147].

Membrane fluidity also plays an important role in phagocytosis by macrophages [148], the recognition of viral and bacterial infections and the ability of the cell to produce lipid mediators (eicosanoids from AA/EPA/DGLA: e.g. prostaglandins, leukotrienes, thromboxanes, endocannabinoids [149]; docosanoids from DHA: e.g. resolvins and protectins) [150]. These mediators are produced from the AA, EPA and DHA contained in the cell membrane. The process begins when growth factors or hormones activate phospholipase A2, which then releases DGLA, AA, EPA and DHA from the cell membrane. The fatty acids released in this way are then used for the production of the eicosanoids and docosanoids in order to achieve the respective immunological effect [114]. The fatty acids are therefore essential precursors for these lipid mediators, which have key functions in cellular regulation.

\section{How EPA/DHA stop inflammation from LPS and palmitic acid}

In addition to the conversion of EPA/DHA into inflammation resolving messengers (Figure 4), these fats also have a direct anti-inflammatory action. Activation of a cell's TLR4 receptors by lipopolysaccharides (LPS) or palmitic acid leads to activation of the transcription factor NF- $\mathrm{KB}$ $[50,151]$. This causes the expression of inflammatory genes, thus triggering or maintaining inflammation. Consuming long-chain $\omega 3$ fatty acids can activate the GPR120 receptor and thus block the activation of NF- $\mathrm{KB}$ in the cell, which prevents the expression of pro-inflammatory genes [50].

\section{Decisive factors for success with EPA/DHA}

Combination therapy is more promising than monotherapy for practically every therapy with natural substances. In some cases though, considerable success can be achieved even with monotherapy. In ulcerative colitis, a very significant improvement of symptoms was achieved with fish oil 
alone [152]: $5.6 \mathrm{~g}$ of EPA/DHA per day were given for six months. Positive clinical effects were apparent after three months. This shows two fundamental aspects that are crucial for therapeutic success [153]: a high dose and sufficiently long intake. Of course, an intestinal dysfunction should not be treated exclusively with EPA/DHA. In this case, pre- and probiotics [154], curcumin [155, 156] and other natural substances [157] in combination with EPA/ DHA are likely to help more effectively and faster without having to give fish oil in such high doses.

\section{Effects on the microbiome mediated by EPA/DHA}

It has been known for some years that EPA/DHA have a positive effect on the microbiome [158, 159]. Long-chain $\omega 3$ fatty acids enhance the production of intestinal alkaline phosphatase (IAP) by enterocytes. IAP is released into the lumen and reaches the colon in an active form. There it inhibits the growth of E. coli and other gram negative bacteria by dephosphorylating the lipopolysaccharides (LPS) of the bacterial membrane [160]. This reduces the LPS load one of the main triggers of silent inflammation [41]. IAP reduces pro-inflammatory bacteria while increasing those that are anti-inflammatory, which can contribute to resolving intestinal permeability [161]. Greater consumption of EPA and especially DHA also leads to greater microbial diversity [162], which results in better health and a lower risk of metabolic disease [163].

\section{Long chain $\omega 3$ fatty acids - an alternative to statins and painkillers}

Given the many benefits of $\omega 3$ fats, it is justified to ask whether they should be used not just as a supplement to conventional pharmaceutical therapies, but possibly even as a substitute for them. Cardiovascular disease is the leading cause of death in the western world [164, 165]. Statins, which are the standard treatment for hypercholesterolemia, are among the most commonly prescribed drugs $[166,167]$.

A recent meta-analysis of some 115,000 patients showed that statin administration leads to $3 \%$ fewer cardiac deaths than in the control group, although the difference between the statin group and the control group (213 versus 220 cardiac deaths) was not statistically significant. De facto, statins had no benefit in terms of cardiac death [168]. Another meta-analysis revealed that taking $>1 \mathrm{~g} /$ day of
EPA/DHA reduces the risk of cardiac death by $29 \%$ (over 20,000 patients; statistically significant) [169]. Even assuming a $3 \%$ cardiac death reduction by statins, fish oil would still be about ten times more effective.

Much more can probably be achieved with fish oil if the treatment dose and duration are increased, natural triglycerides are used instead of synthetic ethyl esters [153], and the fatty acids in the supplement and subsequently in the body are effectively protected against oxidation. It would also make sense to dose EPA/DHA depending on the patient's level (see omega-3 index below).

Back to the statins: Advertisements by the pharmaceutical industry speak of a $36 \%$ reduction in relative risk of heart attack. In the associated study, the absolute risk had fallen from $3 \%$ (placebo) to $1.9 \%$ (statins), and the all-cause mortality of both groups was identical [170].

The results of 11 clinical studies show that life is statistically prolonged by about two days per year of statin use $[171,172]$. One mechanism that can explain this is that statins can reduce excess iron levels, thereby dampening inflammation [173]. An obvious alternative to this approach would be regular therapeutic phlebotomy or blood donations. The other mechanism that may explain this is that statins reduce TLR4-mediated inflammation in people with a particular TLR4 gene variant $[174,175]$. In this case the consumption of EPA/DHA would be an effective alternative [50]. The price of the minimal life extension from statins that can be attained via other means is a considerable reduction in quality of life.

The multiple side effects of statins can all be attributed to the fact that they intervene in an essential metabolic pathway by blocking HMG-CoA reductase [176]. As a result, it is not just cholesterol synthesis that is reduced, but also that of heme A [177], Q10 [176] and selenoproteins [178], including glutathione peroxidase. The consequences are mitochondrial and cellular damage, muscle pain/weakness, liver damage, peripheral neuropathy, fatigue, shortness of breath, memory loss, heart failure, atherogenesis, carcinogenesis, aging, type 2 diabetes, immunosuppression, and deficiency of steroid hormones (vitamin D, progesterone, testosterone, oestrogen, cortisol, aldosterone) as well as bile acid [173, 176-180].

In addition, several studies on cholesterol call into question the utility of statins. As the total cholesterol level increases, mortality decreases significantly, which was shown in a study involving more than 170,000 Japanese [181], but also in a smaller Dutch study [182]. One possible explanation is that cholesterol protects against infections and cancer [182-184]. The same phenomenon can be seen with LDL cholesterol. Here, too, an increase leads to a decrease in mortality $[181,185]$.

Only in cases of familial hypercholesterolemia may statin treatment be appropriate. Hormone therapy has been 
suggested as an alternative, but that approach has not yet been sufficiently researched $[186,187]$.

In light of these studies, it is remarkable that statins are the standard of care for all patients with cardiovascular risks/diseases according to guidelines set by the Drug Commission of the German Medical Association. The same daily dose (40 mg of simvastatin) is recommended for everyone, regardless of whether they already have a cardiovascular disease or only an increased risk [167]. Statins as first line treatment are similarly emphasized in other countries $[188,189]$.

Diagnostically, oxidized LDL as a major cause of cardiovascular disease could be a useful alternative to current cholesterol diagnostics [77, 190, 191]. With oxidized LDL having strong links to inflammation [192], antiinflammatory nutrient-based prevention and therapy appear even more relevant [60].

EPA/DHA can also be an alternative to standard painkillers (non-steroidal anti-inflammatory drugs like aspirin, ibuprofen or diclofenac). In a study of 125 patients suffering from disc or arthritic spinal pain and taking painkillers, $2.4 \mathrm{~g}$ and later $1.2 \mathrm{~g}$ of EPA/DHA were given daily. Nearly $60 \%$ of the patients were able to discontinue their painkillers and the joint pain was reduced by the same figure. $80 \%$ of patients were satisfied with their improvements [193].

Figure 5 shows the wide range of indications for EPA/ DHA. Since silent inflammation is either causally for or at least closely related to almost all chronic diseases in developed countries [194, 195], the fields of use for these fatty acids are correspondingly broad. Just as numerous are the drugs that can be meaningfully supplemented or replaced by them alone, or if necessary in combination with further anti-inflammatory measures.

In principle, there is a high probability that EPA/DHA will contribute to the resolution of inflammation and thus positively influence the course of the disease, even for many diseases not explicitly mentioned in Figure 5 . The combined administration of vitamin D3 and EPA/DHA, for instance, has had definite health benefits for multiple sclerosis patients [196].

\section{How to handle fatty acids in everyday life}

The media and scientific literature frequently provide information on a supposedly ideal $\omega 6 / \omega 3$ fatty acid ratio in the diet. Unfortunately, often no distinction is made between short-chain (LA, ALA) and long-chain fatty acids (AA, EPA/DHA) [197]. This is crucial in view of the often low conversion of short- to long-chain fatty acids. Important factors for individual differences are pre-existing conditions (diabetes), BMI, genetics, alcohol consumption, social status, hormone treatment, gender, age, and vitamin/mineral levels [126].

Looking at the population as a whole, some factors are positively associated with EPA/DHA levels (female, below 50 , wine consumption, intake of long chain $\omega 3$ fatty acid as triglycerides), and some negatively (genetics, BMI, smoking). However, the decisive factors are - hardly surprisingly - fish and fish oil consumption [198]. To prescribe a really effective and tailormade therapy for the patient, measuring the omega-3 Index is very helpful.

In addition to the direct intake of oils, it is also important to take a look at diet. Beyond reducing carbohydrate and especially fructose consumption, which is frequently advisable, it is also instructive to consider the feedstock of the meat being consumed. Meat of cattle fed on cereals has a $\omega 6 / \omega 3$ ratio of $8: 1$, while that of grass-fed animals is very different, at 2:1 [199].

A similar picture emerges when farmed salmon is compared with wild salmon. Farmed salmon contains about 10 times more $\omega 6$-fats, but fewer environmental toxins [200]. Ideally, one would regularly consume $\omega 3$-rich wild fish that has been tested for contaminants. Unfortunately this is nigh on impossible for most consumers and, in addition, some people simply do not like to eat fish.

Fatty acids are reactive at their double bonds, which makes them increasingly sensitive to rancidity as the number of these double bonds increases. Light, heat and oxygen can damage fatty acids by forming radicals [201, 202]. LA is still relatively stable, but ALA already much less so, while EPA and most of all DHA are highly sensitive. After opening, bottles of fish oil should be used up within 6-8 weeks, and always kept in the refrigerator. Storing fish oil at $-18^{\circ} \mathrm{C}$ can double its shelf life [203].

For frying, largely saturated fats such as coconut oil, butterfat or lard are useful, as they are heat-stable and insensitive to oxidation due to their lack of double bonds. Extra virgin olive oil has been found to be even more heat-stable than coconut fat and avocado oil, probably because of its high content of antioxidative polyphenols [204]. All these fats are suitable for cooking.

In principle, all fats are suitable for use when unheated. For smoothies $\omega 3$-fats should be added last. The introduction of oxygen via blending reduces the stability of these fats [205], and smoothies should be consumed as soon as possible after preparation.

$\omega 6$ fats in the western diet are often of low quality: they are frequently oxidized $[205,206]$ and contain trans fats [207]. Supermarkets are full of seed oils, which, after extraction and refining, are no longer protected from oxidation. If these oils are used for frying, oxidation and the amount of trans fats increase considerably [208]. Ideally, $\omega 6$ fats should only be consumed in the form of natural foods. 


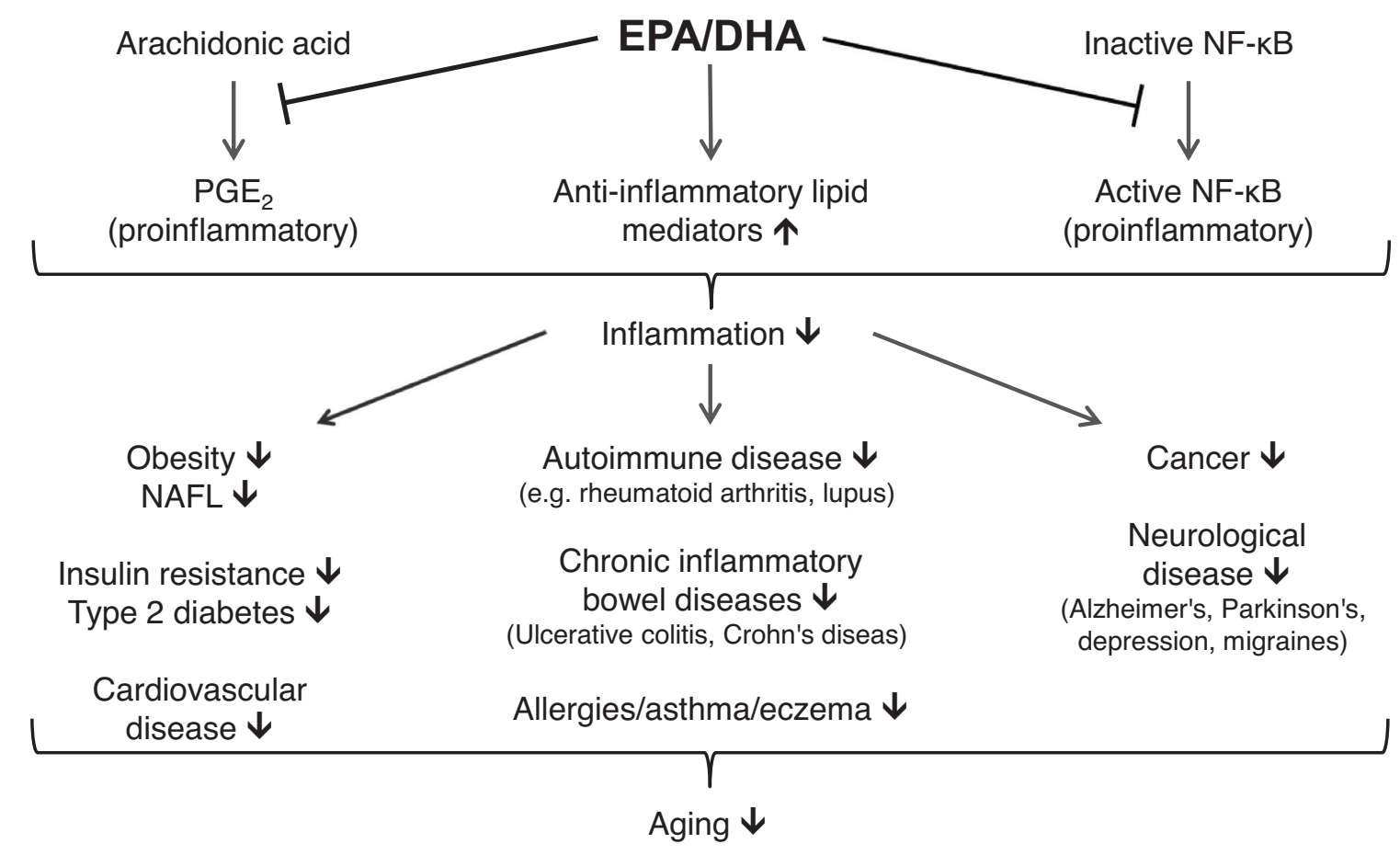

Figure 5. Positive effects of EPA/DHA: The long-chain $\omega 3$ fatty acids (EPA/DHA) reduce the formation of pro-inflammatory factors and at the same time increase the amount of anti-inflammatory ones. This has a beneficial impact on a large number of diseases that are closely related to

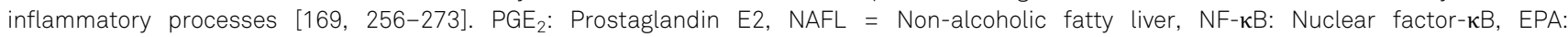
Eicosapentaenoic acid, DHA: Docosahexaenoic acid.

If additional intake is required, the oils need to be well protected against oxidation.

It is essential to avoid industrially produced trans fats such as those frequently found in margarines, processed foods, baked goods and deep-fried foods [209]. Labels such as organic or vegan do not offer any protection as they only refer to the raw materials, not to the processing. When eating out, it can be useful to request that olive oil or butter is used for frying.

Therapeutically, wild-caught, fatty cold-water fish is ideal as a source of EPA/DHA if it is toxin-free. The preparation is also critical: broiling or baking is far preferable to frying which damages the sensitive $\omega 3$ fatty acids $[210,211]$.

Alternatively, fish or krill oil preparations may be used where the toxins have been removed via distillation. Krill oil is often advertised as having better bioavailability, but this has not been confirmed in studies [198]. Both have similar bioavailability [212], so fish oil usually offers greater value for money where EPA/DHA are concerned. It is crucial that fish oil is consumed with a meal containing fat from other sources to ensure good absorption [198].

Furthermore, it is important to have realistic expectations of how long it is likely to take to see results. If suffering from a clinically relevant deficit in EPA/DHA, it will take weeks to months for functional pools to incorporate their maximal amounts of these fatty acids [213]. Three to four months appears to be a realistic time frame to fully benefit from the consumption of EPA/DHA [152].

\section{Basis for therapy: the omega-3 index as a great analytical tool}

The $\omega 3 / \omega 6$ ratio in humans is neither precise nor specific as a metric, and different analysis methodologies, different lipid compartments (whole blood, red blood cells, plasma, phospholipids, triglycerides, etc.) and criteria (measuring all $\omega 3$ and $\omega 6$ fatty acids or only the "most important" ones) lead to very different results. Additionally, some misconceptions have developed historically. It has been shown to be incorrect that increased LA intake (of which only $<0.2 \%$ is converted into $\mathrm{AA}$ ) or even direct $\mathrm{AA}$ intake increases inflammation in healthy individuals, as one example. It is rather the lack of EPA/DHA that is responsible for inflammation not subsiding. Accordingly, merely reducing $\omega 6$ consumption is not helpful and often not desirable, since a lower AA level is associated with increased cardiovascular risk [214]. Another aspect is that the $\omega 6$ fatty acids LA, GLA and DGLA are associated with reduced overall mortality, while AA is neutral in this respect. Only the littleresearched long-chain $\omega 6$ fatty acids docosatetraenoic acid 
(22:4 $\omega 6=$ DTA $=$ adrenic acid $)$ and docosapentaenoic acid $(22: 5 \omega 6=\omega 6-\mathrm{DPA})$ increase inflammation and mortality [215]. DTA and $\omega 6-D P A$ are synthesized from AA in lipid metabolism [216, 217]. Taken together, this renders the use of an $\omega 3 / \omega 6$ ratio to assess a patient's fatty acid status quo absurd.

A suitable alternative is the now well-established omega-3 index [214]. This index reflects the proportion of EPA + DHA in percent, by weight, of all fatty acids in the membrane of the red blood cells. It also represents an independent risk factor for cardiovascular diseases. A range of $8-11 \%$ is desirable to reduce the risk of these and other diseases $[137,218]$. This range is safe and probably useful for the vast majority of preventive and therapeutic applications; higher values generally do not appear to provide additional benefit [219]. An omega-3 index of $\geq 16 \%$ should be avoided to prevent increased bleeding [137]. Many laboratories across the world offer an omega-3 index analysis. EPA/DHA consumption can then be adjusted according to the patient's results. This test, which can usually be performed via fingerprick, is extremely useful in clinical practice. The results can be used to motivate the patient to make dietary changes and, if necessary, to supplement the diet with fish oil.

Several studies that apparently did not achieve statistically relevant, positive results after the administration of EPA/DHA used insufficient criteria for selecting the test persons. In the future, subjects with a low omega-3 index should be selected and then provided with EPA/DHA such that their index is increased to $8-11 \%$. This is likely to yield reproducible, statistically significant clinical success. Such successes have so far been rather random, requiring the study population to have a homogeneously low index at the beginning [137]. In other words, those who already have sufficient EPA/DHA in their cells are unlikely to benefit from additional intake. Substitution only makes sense if the individual is suffering from a deficiency.

\section{How to protect fish oils against rancidity in the bottle and the body}

Increased EPA/DHA consumption leads to greater incorporation of these fatty acids into the cell membrane. These highly unsaturated fatty acids with five or six double bonds are very susceptible to radical formation. In nature, polyunsaturated fats always occur together with plenty of antioxidants [220], or are shielded from oxygen as in seeds. This should be imitated in the best way possible if supplements are used. Whenever EPA/DHA are administered in higher dosages without suitable antioxidants, these oxidation-sensitive fatty acids can contribute to oxidative stress and silent inflammation with its numerous related diseases. To prevent this and fully benefit from the healing effects of EPA/DHA even at high doses, the simultaneous administration of fat-soluble antioxidants seems advisable [221, 222]. Exactly this is the physiological function of vitamin $\mathrm{E}$, which makes it very useful to add vitamin $\mathrm{E}$ to fish oil preparations to prevent $\omega 3$ fats from becoming rancid, both in the bottle/capsule and after oral uptake in the body and ultimately in the cell membrane [21,223]. At the same time, vitamin $\mathrm{E}$ has the potential to prevent an increase in plasma glucose concentration, which has been observed with the sole administration of polyunsaturated fats [224]. The use of multiple fat-soluble antioxidants can be helpful to achieve comprehensive protection of these vulnerable fatty acids. Astaxanthin, for example, is another attractive candidate, as this molecule is incorporated into the cell membrane and can thus protect $\omega 3$ fats efficiently at their destination [225]. In addition, synergistic effects have been shown for the combination of EPA/DHA and astaxanthin [226].

Further key measures to protect EPA/DHA include processing fish fresh from the catch within 24 hours, bottling under a nitrogen atmosphere and the use of amber glass bottles if capsules are not used. These measures protect the sensitive fatty acids from oxygen, light and heat [201, 202]. Contamination with heavy metals such as mercury, dioxins and polychlorinated biphenyls (PCBs) is practically non-existent in modern fish oils due to molecular distillation [227-230]. Protection against oxidation should thus be the focus of the critical consumer [231].

\section{Fish oil dosage - is there reason to fear too much of a good thing?}

The suitable dosage for a patient depends on their fish consumption and omega- 3 index. It should be adjusted so that the patient reaches the optimal range of this index. Between 0.5 and $4 \mathrm{~g}$ of EPA+DHA per day were typically used in studies. In general, the consumption of fish oil is very safe. Even the discontinuation before surgery usually recommended does not seem necessary [232]. A dosage of almost $7 \mathrm{~g} \mathrm{EPA+DHA}$ per day for half a year has no negative influence on blood clotting [233]. Thus, even such an extremely high dosage appears possible.

Another approach to determine a reasonable dosage is to look at gene expression. Giving fish oil at a dose of $1.8 \mathrm{~g}$ EPA+DHA/day for 26 weeks changed the expression of 1,040 genes in test persons. A lower expression of genes involved in inflammatory and atherogenic metabolic pathways was noted [234]. This strongly suggests that a daily dosage of just under $2 \mathrm{~g}$ of EPA+DHA taken for six months 
is realistic to achieve therapeutic effects. The omega-3 index should of course be factored in to adjust for individual needs [218].

One should also consider that monotherapy is generally not the best avenue for holistic therapy, despite the fact that this is usually a prerequisite for scientific studies. In a holistic approach, moderate quantities in the range of 1-3 $\mathrm{g}$ EPA +DHA per day [169] should be sufficient in most cases. Also, the importance of the long chain $\omega 3$ fatty acids should not result in a complete avoidance of the $\omega 6$ counterpart as their functions are just as essential. AA has many important physiological functions with great significance for health, including the following: membrane fluidity, initiation of inflammation, neonatal development, endocannabinoids, nervous system, immune response, musculature, resistance to parasites, anti-tumour activity and apoptosis [105].

An important aspect when assessing the dosage of EPA/ DHA in clinical trials is that in most studies the ethyl ester form of these fatty acids was given and not the better natural triglyceride form $[235,236]$ together with suitable antioxidants. If both are ensured, one can expect an even better effect from fish oil. A dose of $1 \mathrm{~g}$ of EPA+DHA per day with a meal might be sufficient for general prevention.

\section{Conclusion}

In the treatment of chronic inflammatory processes and the diseases arising from them, the objective should not be to block inflammation, which is fundamentally necessary for survival. Rather, the aim should be to provide the best possible support for the resolution of inflammatory processes that have fulfilled their purpose. The long-chain $\omega 3$ fats EPA/DHA can make a vital contribution to this in the context of a wide range of diseases. The omega-3 index is a useful analytical tool for calibrating the tailored supplementation of these valuable fatty acids, both as a baseline and for monitoring therapy. Beyond the regular consumption of these critically important long-chain $\omega 3$ fatty acids there are a few rules of thumb when it comes to fatty acids. Saturated fats from food should not be feared but palmitic acid that the body makes due to an overconsumption of fructose can be very problematic and pro-inflammatory. Manmade trans fatty acids should be avoided as much as possible but nature made trans fatty acids are a healthy part of people's diets. One should beware of manmade conjugated linoleic acid (CLA) since it is very different from what can be found in butter. In general, traditional fats are preferable to modern seed oils. Arachidonic acid should not be avoided at all costs. It is essential to health but needs to be balanced with EPA/DHA.

\section{References}

1. Astrup A, Bertram HCS, Bonjour J-P, de Groot LCP, de Oliveira Otto MC, Feeney EL, et al. WHO draft guidelines on dietary saturated and trans fatty acids: time for a new approach? BMJ. 2019;366:14137.

2. Liu AG, Ford NA, Hu FB, Zelman KM, Mozaffarian D, KrisEtherton PM. A healthy approach to dietary fats: understanding the science and taking action to reduce consumer confusion. Nutr J. 2017;16(1):53.

3. Ioannidis JPA. The challenge of reforming nutritional epidemiologic research. JAMA. 2018;320(10):969-70.

4. Archer E, Pavela G, Lavie CJ. The inadmissibility of what we eat in America and NHANES dietary data in nutrition and obesity research and the scientific formulation of national dietary guidelines. Mayo Clin Proc. 2015;90(7):911-26.

5. Dhurandhar NV, Schoeller D, Brown AW, Heymsfield SB, Thomas D, Sorensen TI, et al. Energy balance measurement: when something is not better than nothing. Int $\mathrm{J}$ Obes (Lond) 2015;39(7):1109-13.

6. Nestle M. Food politics: How the food industry influences nutrition and health. 10th ed: University of California Press: 2013. p. 534

7. Stuckler D, Nestle M. Big food, food systems, and global health. PLoS Med. 2012;9(6): e1001242.

8. Nestle M. Unsavory Truth: How Food Companies Skew the Science of What We Eat. Basic Books; 2018.

9. Eaton SB, Konner M. Paleolithic nutrition. A consideration of its nature and current implications. N Engl J Med. 1985;312 (5):283-289.

10. Simopoulos AP. Evolutionary aspects of diet: the omega-6/ omega-3 ratio and the brain. Mol Neurobiol. 2011;44(2):20315.

11. Kaur N, Chugh V, Gupta AK. Essential fatty acids as functional components of foods - a review. J Food Sci Technol. 2014;51(10):2289-303.

12. Raederstorff D, Wyss A, Calder PC, Weber P, Eggersdorfer M. Vitamin E function and requirements in relation to PUFA. Br J Nutr. 2015;114(8):1113-22.

13. Furman D, Campisi J, Verdin E, Carrera-Bastos P, Targ S, Franceschi $\mathrm{C}$, et al. Chronic inflammation in the etiology of disease across the life span. Nature Medicine. 2019;25 (12):1822-32.

14. Kingston A, Robinson L, Booth $H$, Knapp M, Jagger $C$. Projections of multi-morbidity in the older population in England to 2035: estimates from the Population Ageing and Care Simulation (PACSim) model. Age Ageing. 2018;47(3): 374-80.

15. Freeman KS. U.S. lives: longer but sicker? Environ Health Perspect. 2011;119(3):a118.

16. Safran B. (magazine cover) The Fat of the Land. Time Magazine. January; 13, 1961.

17. Helms S. Das Gezerre um das liebe Fett. Stern; 2014.

18. Ravnskov U, Pollmer U, Warmuth S. Mythos Cholesterin: Die zehn größten Irrtümer. 5th ed. S. Hirzel Verlag; 2010.

19. Taubes G. Good calories, bad calories: fats, carbs, and the controversial science of diet and health. Anchor; 2008.

20. Ravnskov U. The cholesterol myths: exposing the fallacy that saturated fat and cholesterol cause heart disease. New Trends Publishing Inc, US; 2000.

21. Stipanuk MH, Caudill MA. Biochemical, physiological, and molecular aspects of human nutrition. 3th ed. Saunders: 2012. 
22. Keys A. Atherosclerosis: a problem in newer public health. J Mt Sinai Hosp N Y. 1953;20(2):118-39.

23. Yerushalmy J, Hilleboe HE. Fat in the diet and mortality from heart disease; a methodologic note. N Y State $J$ Med. 1957;57(14):2343-54.

24. Pett KD, Willett WC, Vartiainen E, Katz DL. The seven countries study. Eur Heart J. 2017;38(42):3119-21.

25. Choi SW, Tran DH. Heart attacks prevent chocolate. Or, the differences between correlation and causation. Anaesthesia. 2016;71(5):586-9.

26. Harcombe Z. US dietary guidelines: is saturated fat a nutrient of concern? Br J Sports Med. 2018.

27. O'Connor TP, Campbell TC. Potential responses to and impacts of epidemiological and experimental data on dietary fat and cancer. Dietary guidelines. Prog Clin Biol Res. 1986; 222:731-71.

28. Harcombe Z, Baker JS, Cooper SM, Davies B, Sculthorpe N, DiNicolantonio JJ, et al. Evidence from randomised controlled trials did not support the introduction of dietary fat guidelines in 1977 and 1983: a systematic review and metaanalysis. Open Heart. 2015;2(1):e000196.

29. DiNicolantonio JJ, Harcombe Z, O'Keefe JH. Problems with the 2015 dietary guidelines for Americans: an alternative. Mo Med. 2016:113(2):93-7.

30. Ravnskov U, DiNicolantonio JJ, Harcombe Z, Kummerow FA, Okuyama H, Worm N. The questionable benefits of exchanging saturated fat with polyunsaturated fat. Mayo Clin Proc. 2014;89(4):451-3.

31. Harcombe Z. Designed by the food industry for wealth, not health: the 'Eatwell Guide'. Br J Sports Med. 2017;51 (24):1730-1.

32. Harcombe Z, Baker JS, Davies B. Food for thought: have we been giving the wrong dietary advice? Food Nutr Sci. 2013; 04:240-4.

33. Kearns CE, Schmidt LA, Glantz SA. Sugar industry and coronary heart disease research: a historical analysis of internal industry documents. JAMA Intern Med. 2016;176 (11):1680-5

34. Domonoske C. 50 years ago, sugar industry quietly paid scientists to point blame at fat. National Public Radio, Inc; 2016.

35. Lim JS, Mietus-Snyder M, Valente A, Schwarz JM, Lustig RH. The role of fructose in the pathogenesis of NAFLD and the metabolic syndrome. Nat Rev Gastroenterol Hepatol. 2010; 7(5):251-64.

36. Hannou SA, Haslam DE, McKeown NM, Herman MA. Fructose metabolism and metabolic disease. J Clin Invest. 2018;128(2):545-55.

37. Jang C, Hui S, Lu W, Cowan AJ, Morscher RJ, Lee G, et al. The small intestine converts dietary fructose into glucose and organic acids. Cell Metab. 2018;27(2):351-61 e3.

38. Lyssiotis CA, Cantley LC. Metabolic syndrome: F stands for fructose and fat. Nature. 2013;502(7470):181-2.

39. Watt MJ, Hoy AJ, Muoio DM, Coleman RA. Distinct roles of specific fatty acids in cellular processes: implications for interpreting and reporting experiments. Am J Physiol Endocrinol Metab. 2012;302(1):E1-3.

40. Bourassa MW, Alim I, Bultman SJ, Ratan RR. Butyrate, neuroepigenetics and the gut microbiome: Can a high fiber diet improve brain health? Neurosci Lett. 2016;625:56-63.

41. Waehler R. Präbiotika und die Behandlung des metabolischen Syndroms. OM \& Ernährung. 2015;152:F11-F8.

42. German JB, Dillard CJ. Saturated fats: a perspective from lactation and milk composition. Lipids. 2010;45(10): 915-23.
43. Sharma A, Bemis M, Desilets AR. Role of medium chain triglycerides $(A x o n a(R))$ in the treatment of mild to moderate alzheimer's disease. Am J Alzheimers Dis Other Demen. 2014;29(5):409-14.

44. Fortier M, Castellano CA, Croteau E, Langlois F, Bocti C, St-Pierre $\mathrm{V}$, et al. A ketogenic drink improves brain energy and some measures of cognition in mild cognitive impairment. Alzheimers Dement. 2019;15(5):625-34.

45. Cardoso DA, Moreira AS, de Oliveira GM, Raggio Luiz R, Rosa G. A coconut extra virgin oil-rich diet increases HDL cholesterol and decreases waist circumference and body mass in coronary artery disease patients. Nutr Hosp. 2015:32(5):2144-52.

46. Fatima S, Hu X, Gong RH, Huang C, Chen M, Wong HLX, et al. Palmitic acid is an intracellular signaling molecule involved in disease development. Cell Mol Life Sci. 2019;76(13):2547-57.

47. Carta G, Murru E, Banni S, Manca C. Palmitic acid: Physiological role, metabolism and nutritional implications. Front Physiol. 2017;8:902.

48. Lustig RH. Fructose: it's "alcohol without the buzz". Adv Nutr. 2013:4(2):226-35.

49. Harris WS, Zotor FB. n-3 Fatty acids and risk for fatal coronary disease. Proc Nutr Soc. 2019;1-6.

50. Rogero MM, Calder PC. Obesity, inflammation, toll-like receptor 4 and fatty acids. Nutrients. 2018;10(4).

51. Louheranta AM, Turpeinen AK, Schwab US, Vidgren HM, Parviainen MT, Uusitupa MI. A high-stearic acid diet does not impair glucose tolerance and insulin sensitivity in healthy women. Metabolism. 1998;47(5):529-34.

52. Meng H, Matthan NR, Wu D, Li L, Rodriguez-Morato J, Cohen R, et al. Comparison of diets enriched in stearic, oleic, and palmitic acids on inflammation, immune response, cardiometabolic risk factors, and fecal bile acid concentrations in mildly hypercholesterolemic postmenopausal women-randomized crossover trial. Am J Clin Nutr. 2019.

53. Tholstrup T, Marckmann P, Jespersen J, Sandstrom B. Fat high in stearic acid favorably affects blood lipids and factor VII coagulant activity in comparison with fats high in palmitic acid or high in myristic and lauric acids. Am J Clin Nutr. 1994;59(2):371-7.

54. Evans LM, Cowey SL, Siegal GP, Hardy RW. Stearate preferentially induces apoptosis in human breast cancer cells. Nutr Cancer. 2009;61(5):746-53.

55. Hoenselaar R. Further response from Hoenselaar. Br J Nutr. 2012;108(5):939-42.

56. Ravnskov U. Lack of evidence that saturated fat causes cardiovascular disease. BMJ. 2014;348: g3205.

57. Siri-Tarino PW, Sun Q, Hu FB, Krauss RM. Meta-analysis of prospective cohort studies evaluating the association of saturated fat with cardiovascular disease. Am J Clin Nutr. 2010;91(3):535-46.

58. Ruiz-Nunez B, Dijck-Brouwer DA, Muskiet FA. The relation of saturated fatty acids with low-grade inflammation and cardiovascular disease. J Nutr Biochem. 2016;36:1-20.

59. Gershuni VM. Saturated fat: part of a healthy diet. Curr Nutr Rep. 2018;7(3):85-96.

60. Malhotra A, Redberg RF, Meier P. Saturated fat does not clog the arteries: coronary heart disease is a chronic inflammatory condition, the risk of which can be effectively reduced from healthy lifestyle interventions. Br J Sports Med. 2017; 51(15):1111-2.

61. Hall KD, Ayuketah A, Brychta R, Cai H, Cassimatis T, Chen KY, et al. Ultra-processed diets cause excess calorie intake and weight gain: an inpatient randomized controlled trial of ad libitum food intake. Cell Metab. 2019. 
62. Remig V, Franklin B, Margolis S, Kostas G, Nece T, Street JC. Trans fats in America: a review of their use, consumption, health implications, and regulation. J Am Diet Assoc. 2010; 110(4):585-92.

63. Ferreri C, Panagiotaki M, Chatgilialoglu C. Trans fatty acids in membranes: the free radical path. Mol Biotechnol. 2007; 37(1):19-25.

64. Kuhnt K, Degen C, Jahreis G. Evaluation of the impact of ruminant trans fatty acids on human health: important aspects to consider. Crit Rev Food Sci Nutr. 2016;56(12): 1964-80.

65. Van Vranken D, Weiss GA. Introduction to bioorganic chemistry and chemical biology. Garland Science; 2012. p. 504.

66. Graham TG, Ramsey D. The happiness diet: a nutritional prescription for a sharp brain, balanced mood, and lean, energized body. 2012.

67. Measuring Worth. Available from: https://www.measuringworth. com/index.php

68. Fenster MS. When Tradition Trumps Science; 2016. Available from: https://www.psychologytoday.com/us/blog/you-arewhat-you-eat/201604/when-tradition-trumps-science

69. Tye L. The Father of Spin. Edward L. Bernays \& the Birth of Public Relations; 1998.

70. DiNicolantonio J, Mercola J. Superfuel: Ketogenic keys to unlock the secrets of good fats, bad fats, and great health. 1st ed. Hay House Inc.; 2018. p. 237.

71. Enig MG. Know your fats: The complete primer for understanding the nutrition of fats. Bethesda Pr; 2000.

72. Ginter E, Simko V. New data on harmful effects of trans-fatty acids. Bratisl Lek Listy. 2016;117(5):251-3.

73. Wilczek MM, Olszewski R, Krupienicz A. Trans-fatty acids and cardiovascular disease: urgent need for legislation. Cardiology. 2017;138(4):254-8.

74. Niu SL, Mitchell DC, Litman BJ. Trans fatty acid derived phospholipids show increased membrane cholesterol and reduced receptor activation as compared to their cis analogs. Biochemistry. 2005;44(11):4458-65.

75. Oteng $A B$, Kersten $S$. Mechanisms of action of trans fatty acids. Adv Nutr. 2020;11(3):697-708.

76. Kummerow FA. The negative effects of hydrogenated trans fats and what to do about them. Atherosclerosis. 2009;205(2): 458-65.

77. Kummerow FA. Two lipids in the diet, rather than cholesterol, are responsible for heart failure and stroke. Clinical Lipidology. 2014;9(2):189-204.

78. Kuhnt K, Baehr M, Rohrer C, Jahreis G. Trans fatty acid isomers and the trans-9/trans-11 index in fat containing foods. Eur J Lipid Sci Technol. 2011;113(10):1281-92.

79. Künstliche Transfette in Nahrungsmitteln begrenzen. Springer Medizin; 2018. Available from: https://www. aerztezeitung.de/politik_gesellschaft/gesundheitspolitik_ international/article/973040/eu-kommission-plantkuenstliche-transfette-nahrungsmitteln-begrenzen.html

80. Dewey C. Artificial trans fats, widely linked to heart disease, are officially banned. The Washington Post; 2018

81. de Souza RJ, Mente A, Maroleanu A, Cozma Al, Ha V, Kishibe $T$, et al. Intake of saturated and trans unsaturated fatty acids and risk of all cause mortality, cardiovascular disease, and type 2 diabetes: systematic review and metaanalysis of observational studies. BMJ. 2015;351:h3978.

82. Kiage JN, Merrill PD, Robinson CJ, Cao Y, Malik TA, Hundley BC, et al. Intake of trans fat and all-cause mortality in the Reasons for Geographical and Racial Differences in Stroke (REGARDS) cohort. Am J Clin Nutr. 2013;97(5): 1121-8.
83. Chin SF, Liu W, Storkson JM, Ha YL, Pariza MW. Dietary sources of conjugated dienoic isomers of linoleic acid, a newly recognized class of anticarcinogens. J Food Compost Anal. 1992;5(3):185-97.

84. Dhiman TR, Anand GR, Satter LD, Pariza MW. Conjugated linoleic acid content of milk from cows fed different diets. J Dairy Sci. 1999;82(10):2146-56.

85. Smit LA, Baylin A, Campos H. Conjugated linoleic acid in adipose tissue and risk of myocardial infarction. Am J Clin Nutr. 2010;92(1):34-40.

86. Biong AS, Veierod MB, Ringstad J, Thelle DS, Pedersen JI. Intake of milk fat, reflected in adipose tissue fatty acids and risk of myocardial infarction: a case-control study. Eur J Clin Nutr. 2006;60(2):236-44.

87. Bonthuis M, Hughes MC, Ibiebele TI, Green AC, van der Pols JC. Dairy consumption and patterns of mortality of Australian adults. Eur J Clin Nutr. 2010;64(6):569-77.

88. Warensjo E, Smedman A, Stegmayr B, Hallmans G, Weinehall L, Vessby B, et al. Stroke and plasma markers of milk fat intake a prospective nested case-control study. Nutr J. 2009;8:21.

89. Jakobsen MU, Bysted A, Andersen NL, Heitmann BL, Hartkopp HB, Leth T, et al. Intake of ruminant trans fatty acids and risk of coronary heart disease - an overview. Atheroscler Suppl. 2006;7(2):9-11.

90. Kramer JK, Parodi PW, Jensen RG, Mossoba MM, Yurawecz MP, Adlof RO. Rumenic acid: a proposed common name for the major conjugated linoleic acid isomer found in natural products. Lipids. 1998;33(8):835.

91. Pestana JM, Martins SIV, Alfaia CMM. Content and distribution of conjugated linoleic acid isomers in bovine milk, cheese and butter from Azores. Dairy Sci Technol. 2009;89 (193):193-200.

92. Riserus U, Basu S, Jovinge S, Fredrikson GN, Arnlov J, Vessby B. Supplementation with conjugated linoleic acid causes isomer-dependent oxidative stress and elevated C-reactive protein: a potential link to fatty acid-induced insulin resistance. Circulation. 2002;106(15):1925-9.

93. Benjamin S, Prakasan P, Sreedharan S, Wright AD, Spener F. Pros and cons of CLA consumption: an insight from clinical evidences. Nutr Metab (Lond). 2015;12:4.

94. Sales-Campos H, Souza PR, Peghini BC, da Silva JS, Cardoso CR. An overview of the modulatory effects of oleic acid in health and disease. Mini Rev Med Chem. 2013;13(2): 201-10.

95. de Souza CO, Valenzuela CA, Baker EJ, Miles EA, Rosa Neto JC, Calder PC. Palmitoleic acid has stronger anti-inflammatory potential in human endothelial cells compared to oleic and palmitic acids. Mol Nutr Food Res. 2018;62(20):e1800322.

96. de Souza CO, Vannice GK, Rosa Neto JC, Calder PC. Is palmitoleic acid a plausible nonpharmacological strategy to prevent or control chronic metabolic and inflammatory disorders? Mol Nutr Food Res. 2018;62(1).

97. Morse N. Are some health benefits of palmitoleic acid supplementation due to its effects on $5^{\prime}$ adenosine monophosphate-activated protein kinase (AMPK)? Lipid Technology. 2015;27(12):278-81.

98. Bernstein AM, Roizen MF, Martinez L. Purified palmitoleic acid for the reduction of high-sensitivity $\mathrm{C}$-reactive protein and serum lipids: a double-blinded, randomized, placebo controlled study. J Clin Lipidol. 2014;8(6):612-7.

99. Bueno-Hernandez N, Sixtos-Alonso MS, Milke Garcia MDP, Yamamoto-Furusho JK. Effect of Cis-palmitoleic acid supplementation on inflammation and expression of HNF4gamma, HNF4alpha and IL6 in patients with ulcerative colitis. Minerva Gastroenterol Dietol. 2017;63(3):257-63. 
100. Lehner A, Staub K, Aldakak L, Eppenberger P, Ruhli F, Martin RD, et al. Impact of omega-3 fatty acid DHA and EPA supplementation in pregnant or breast-feeding women on cognitive performance of children: systematic review and meta-analysis. Nutr Rev. 2020.

101. Le HD, Meisel JA, de Meijer VE, Gura KM, Puder M. The essentiality of arachidonic acid and docosahexaenoic acid. Prostaglandins Leukot Essent Fatty Acids. 2009;81(2-3): 165-70.

102. Johnson GH, Fritsche K. Effect of dietary linoleic acid on markers of inflammation in healthy persons: a systematic review of randomized controlled trials. J Acad Nutr Diet. 2012;112(7):1029-41, 41 e1-15

103. DiNicolantonio JJ, O'Keefe JH. Omega- 6 vegetable oils as a driver of coronary heart disease: the oxidized linoleic acid hypothesis. Open Heart. 2018;5(2):e000898.

104. Silva JR, Burger B, Kuhl CMC, Candreva T, Dos Anjos MBP, Rodrigues HG. Wound healing and omega- 6 fatty acids: from inflammation to repair. Mediators Inflamm. 2018;2018: 2503950.

105. Tallima H, El Ridi R. Arachidonic acid: Physiological roles and potential health benefits - A review. J Adv Res. 2018; 11:33-41.

106. Calder PC, Campoy C, Eilander A, Fleith M, Forsyth S, Larsson PO, et al. A systematic review of the effects of increasing arachidonic acid intake on PUFA status, metabolism and health-related outcomes in humans. Br J Nutr. 2019;121(11):1201-14.

107. Maples RD.Arachidonic acid: dietary sources and general functions. Biochemistry research trends. 1st ed. Nova Science Pub Inc; 2012. p. 21-9.

108. Fan YY, Chapkin RS. Importance of dietary gamma-linolenic acid in human health and nutrition. J Nutr. 1998;128(9): 1411-4.

109. Chilton FH, Rudel LL, Parks JS, Arm JP, Seeds MC. Mechanisms by which botanical lipids affect inflammatory disorders. Am J Clin Nutr. 2008;87(2):498S-503S.

110. Barham JB, Edens MB, Fonteh AN, Johnson MM, Easter L, Chilton FH. Addition of eicosapentaenoic acid to gammalinolenic acid-supplemented diets prevents serum arachidonic acid accumulation in humans. J Nutr. 2000;130(8): 1925-31.

111. Das UN. A defect in Delta6 and Delta5 desaturases may be a factor in the initiation and progression of insulin resistance, the metabolic syndrome and ischemic heart disease in South Asians. Lipids Health Dis. 2010;9:130.

112. Timoszuk M, Bielawska K, Skrzydlewska E. Evening Primrose (Oenothera biennis) Biological Activity Dependent on Chemical Composition. Antioxidants (Basel). 2018;7(8).

113. Hussein N, Ah-Sing E, Wilkinson P, Leach C, Griffin BA, Millward DJ. Long-chain conversion of [13C]linoleic acid and alpha-linolenic acid in response to marked changes in their dietary intake in men. J Lipid Res. 2005;46(2):269-80.

114. Das UN. Molecular basis of health and disease; 2011. p. 583.

115. Peluffo RO, Brenner RR. Influence of dietary protein on 6- and 9-desaturation of fatty acids in rats of different ages and in different seasons. J Nutr. 1974;104(7):894-900.

116. Mahfouz M. Effect of dietary trans fatty acids on the delta 5 , delta 6 and delta 9 desaturases of rat liver microsomes in vivo. Acta Biol Med Ger. 1981;40(12):1699-705.

117. Mahfouz MM, Johnson S, Holman RT. The effect of isomeric trans-18:1 acids on the desaturation of palmitic, linoleic and eicosa-8,11,14-trienoic acids by rat liver microsomes. Lipids. 1980;15(2):100-7.

118. Okada Y, Tsuzuki Y, Ueda T, Hozumi H, Sato S, Hokari R, et al. Trans fatty acids in diets act as a precipitating factor for gut inflammation? J Gastroenterol Hepatol. 2013;28 (Suppl 4):29-32.

119. Mozaffarian D. Trans fatty acids - effects on systemic inflammation and endothelial function. Atheroscler Suppl. 2006;7(2):29-32.

120. Mozaffarian D, Aro A, Willett WC. Health effects of transfatty acids: experimental and observational evidence. Eur $\mathrm{J}$ Clin Nutr. 2009;63(Suppl 2):S5-21.

121. Dhaliwal S, Nguyen M, Vaughn AR, Notay M, Chambers CJ, Sivamani RK. Effects of zinc supplementation on inflammatory skin diseases: a systematic review of the clinical evidence. Am J Clin Dermatol. 2020;21(1):21-39.

122. Knez M, Pantovic A, Zekovic M, Pavlovic Z, Glibetic M, Zec M. Is there a link between zinc intake and status with plasma fatty acid profile and desaturase activities in dyslipidemic subjects? Nutrients. 2019;12(1):93.

123. Das UN. Delta6 desaturase as the target of the beneficial actions of magnesium. Med Sci Monit. 2010;16(8):LE11-2.

124. Dattner AM. Chapter 76 - Seborrheic Dermatitis. In: Rakel D, editor. Integrative medicine. 4th ed. Elsevier; 2018. p. 753-8.e1.

125. Das UN. n-3 fatty acids, gamma-linolenic acid, and antioxidants in sepsis. Crit Care. 2013;17(2):312.

126. Das UN. Nutritional factors in the prevention and management of coronary artery disease and heart failure. Nutrition. 2015;31(2):283-91.

127. Burdge GC, Calder PC. Conversion of alpha-linolenic acid to longer-chain polyunsaturated fatty acids in human adults. Reprod Nutr Dev. 2005;45(5):581-97.

128. Burdge GC, Jones AE, Wootton SA. Eicosapentaenoic and docosapentaenoic acids are the principal products of alphalinolenic acid metabolism in young men*. Br J Nutr. 2002; 88(4):355-63.

129. Burdge GC, Wootton SA. Conversion of alpha-linolenic acid to eicosapentaenoic, docosapentaenoic and docosahexaenoic acids in young women. Br J Nutr. 2002;88(4):411-20.

130. Burdge GC. Metabolism of alpha-linolenic acid in humans. Prostaglandins Leukot Essent Fatty Acids. 2006;75(3):161-8.

131. Pawlosky RJ, Hibbeln JR, Novotny JA, Salem N, Jr. Physiological compartmental analysis of alpha-linolenic acid metabolism in adult humans. J Lipid Res. 2001;42(8): 1257-65.

132. Burdge G. n-3 Fatty acid metabolism in women - Reply. Br J Nutr. 2003;90(5):994-5.

133. Pawlosky R, Hibbeln J, Lin Y, Salem N, Jr. n-3 fatty acid metabolism in women. Br J Nutr. 2003;90(5):993-4; discussion 4-5.

134. Greupner T, Kutzner L, Nolte F, Strangmann A, Kohrs H, Hahn A, et al. Effects of a 12-week high-alpha-linolenic acid intervention on EPA and DHA concentrations in red blood cells and plasma oxylipin pattern in subjects with a low EPA and DHA status. Food Funct. 2018;9(3):1587-600.

135. Greupner T, Kutzner L, Pagenkopf S, Kohrs H, Hahn A, Schebb NH, et al. Effects of a low and a high dietary LA/ALA ratio on long-chain PUFA concentrations in red blood cells. Food Funct. 2018;9(9):4742-54.

136. Kawashima $\mathrm{H}$. Intake of arachidonic acid-containing lipids in adult humans: dietary surveys and clinical trials. Lipids Health Dis. 2019;18(1):101.

137. von Schacky C. Verwirrung um die Wirkung von Omega-3Fettsäuren. Der Internist. 2019. https://doi.org/10.1007/ s00108-019-00687-x

138. von Schacky C. Omega-3 index and cardiovascular health. Nutrients. 2014;6(2):799-814.

139. Ernst R, Ejsing CS, Antonny B. Homeoviscous adaptation and the regulation of membrane lipids. J Mol Biol. 2016;428 (24 Pt A):4776-91. 
140. Ibrahim A, Natrajan S, Ghafoorunissa R. Dietary trans-fatty acids alter adipocyte plasma membrane fatty acid composition and insulin sensitivity in rats. Metabolism. 2005;54(2): 240-6.

141. Molugu TR, Brown MF. Cholesterol effects on the physical properties of lipid membranes viewed by solid-state NMR spectroscopy. In: Rosenhouse-Dantsker A, Bukiya AN, editors. Cholesterol modulation of protein function: sterol specificity and indirect mechanisms. Cham: Springer International Publishing; 2019. p. 99-133.

142. Holthuis JC, Menon AK. Lipid landscapes and pipelines in membrane homeostasis. Nature. 2014;510(7503):48-57.

143. Shinitzky M. Membrane fluidity and receptor function. In: Kates M, Manson LA, editors. Membrane fluidity. Boston, MA: Springer US; 1984. p. 585-601.

144. Mirnikjoo B, Brown SE, Kim HF, Marangell LB, Sweatt JD, Weeber EJ. Protein kinase inhibition by omega-3 fatty acids. J Biol Chem. 2001;276(14):10888-96.

145. Ge G, Wu J, Lin Q. Effect of membrane fluidity on tyrosine kinase activity of reconstituted epidermal growth factor receptor. Biochem Biophys Res Commun. 2001;282(2):511-4.

146. Perona JS. Membrane lipid alterations in the metabolic syndrome and the role of dietary oils. Biochim Biophys Acta Biomembr. 2017;1859(9 Pt B):1690-703.

147. Pilon M. Revisiting the membrane-centric view of diabetes. Lipids Health Dis. 2016;15(1):167.

148. Gutierrez S, Svahn SL, Johansson ME. Effects of omega-3 fatty acids on immune cells. Int J Mol Sci. 2019;20(20).

149. Watson JE, Kim JS, Das A. Emerging class of omega-3 fatty acid endocannabinoids \& their derivatives. Prostaglandins Other Lipid Mediat. 2019;143:106337.

150. Wasserman AH, Venkatesan M, Aguirre A. Bioactive lipid signaling in cardiovascular disease, development, and regeneration. Cells. 2020;9(6).

151. Liu T, Zhang L, Joo D, Sun S-C. NF- $\kappa B$ signaling in inflammation. Signal Transduction and Targeted Therapy. 2017:2(1):17023.

152. Almallah YZ, Richardson S, O'Hanrahan T, Mowat NA, Brunt PW, Sinclair TS, et al. Distal procto-colitis, natural cytotoxicity, and essential fatty acids. Am J Gastroenterol. 1998;93(5):804-9.

153. Walker RE, Jackson KH, Tintle NL, Shearer GC, Bernasconi A, Masson S, et al. Predicting the effects of supplemental EPA and DHA on the omega-3 index. The American Journal of Clinical Nutrition. 2019;110(4):1034-40.

154. Couto MR, Goncalves P, Magro F, Martel F. Microbiota-derived butyrate regulates intestinal inflammation: Focus on inflammatory bowel disease. Pharmacol Res. 2020;159:104947.

155. Scazzocchio B, Minghetti L, D’Archivio M. Interaction between Gut Microbiota and Curcumin: A New Key of Understanding for the Health Effects of Curcumin. Nutrients. 2020;12(9).

156. Coelho MR, Romi MD, Ferreira D, Zaltman C, Soares-Mota M. The use of curcumin as a complementary therapy in ulcerative colitis: a systematic review of randomized controlled clinical trials. Nutrients. 2020;12(8).

157. Rossi RE, Whyand T, Murray CD, Hamilton MI, Conte D, Caplin ME. The role of dietary supplements in inflammatory bowel disease: a systematic review. Eur J Gastroenterol Hepatol. 2016;28(12):1357-64.

158. Pusceddu MM, El Aidy S, Crispie F, O'Sullivan O, Cotter P, Stanton C, et al. N-3 polyunsaturated fatty acids (PUFAs) reverse the impact of early-life stress on the gut microbiota. PLoS One. 2015;10(10):e0139721.

159. Mujico JR, Baccan GC, Gheorghe A, Díaz LE, Marcos A. Changes in gut microbiota due to supplemented fatty acids in diet-induced obese mice. Br J Nutr. 2013;110(4):711-20.
160. Kaliannan K, Wang B, Li XY, Kim KJ, Kang JX. A hostmicrobiome interaction mediates the opposing effects of omega- 6 and omega-3 fatty acids on metabolic endotoxemia. Sci Rep. 2015;5:11276.

161. Bilski J, Mazur-Bialy A, Wojcik D, Zahradnik-Bilska J, Brzozowski B, Magierowski M, et al. The role of intestinal alkaline phosphatase in inflammatory disorders of gastrointestinal tract. Mediators Inflamm. 2017;2017:9074601.

162. Menni C, Zierer J, Pallister T, Jackson MA, Long T, Mohney $\mathrm{RP}$, et al. Omega-3 fatty acids correlate with gut microbiome diversity and production of $\mathrm{N}$-carbamylglutamate in middle aged and elderly women. Sci Rep. 2017;7(1):11079.

163. Fang S, Evans RM. Microbiology: Wealth management in the gut. Nature. 2013;500(7464):538-9.

164. WHO. The top 10 causes of death; 2018. Available from: https://www.who.int/news-room/fact-sheets/detail/thetop-10-causes-of-death

165. Pagidipati NJ, Gaziano TA. Estimating deaths from cardiovascular disease: a review of global methodologies of mortality measurement. Circulation. 2013;127(6):749-56.

166. Ramkumar S, Raghunath A, Raghunath S. Statin Therapy: Review of Safety and Potential Side Effects. Acta Cardiol Sin. 2016;32(6):631-9.

167. Arzneimittelkommission der deutschen Ärzteschaft: Handlungsleitlinie Fettstoffwechselstörungen aus Empfehlungen zur Therapie von Fettstoffwechselstörungen. (3. Auflage); 2012.

168. Preiss D, Campbell RT, Murray HM, Ford I, Packard CJ, Sattar N, et al. The effect of statin therapy on heart failure events: a collaborative meta-analysis of unpublished data from major randomized trials. Eur Heart J. 2015;36 (24):1536-46.

169. Maki KC, Palacios OM, Bell M, Toth PP. Use of supplemental long-chain omega-3 fatty acids and risk for cardiac death: An updated meta-analysis and review of research gaps. J Clin Lipidol. 2017;11(5):1152-60 e2.

170. Diamond DM, Ravnskov U. How statistical deception created the appearance that statins are safe and effective in primary and secondary prevention of cardiovascular disease. Expert Rev Clin Pharmacol. 2015;8(2):201-10.

171. Kendrick M. How much longer will you live if you take a statin? 2015. Available from: https://drmalcolmkendrick.org/2015/ 10/27/how-much-longer-will-you-live-if-you-take-a-statin/

172. Kristensen ML, Christensen PM, Hallas J. The effect of statins on average survival in randomised trials, an analysis of end point postponement. BMJ Open. 2015;5(9):e007118.

173. Zacharski LR, DePalma RG, Shamayeva G, Chow BK. The statin-iron nexus: anti-inflammatory intervention for arterial disease prevention. Am J Public Health. 2013;103(4):e105-12.

174. Hodgkinson CP, Ye S. Statins inhibit toll-like receptor 4mediated lipopolysaccharide signaling and cytokine expression. Pharmacogenet Genomics. 2008;18(9):803-13.

175. Katsargyris A, Klonaris C, Tsiodras S, Bastounis E, Giannopoulos A, Theocharis S. Statin treatment is associated with reduced toll-like receptor 4 immunohistochemical expression on carotid atherosclerotic plaques: a novel effect of statins. Vascular. 2011;19(6):320-6.

176. Brookes ZL, McGown CC, Reilly CS. Statins for all: the new premed? Br J Anaesth. 2009;103(1):99-107.

177. Okuyama H, Langsjoen PH, Hamazaki T, Ogushi Y, Hama R, Kobayashi T, et al. Statins stimulate atherosclerosis and heart failure: pharmacological mechanisms. Expert Rev Clin Pharmacol. 2015;8(2):189-99.

178. Moosmann B, Behl C. Selenoproteins, cholesterol-lowering drugs, and the consequences: revisiting of the mevalonate pathway. Trends Cardiovasc Med. 2004;14(7):273-81. 
179. Hu J, Zhang Z, Shen WJ, Azhar S. Cellular cholesterol delivery, intracellular processing and utilization for biosynthesis of steroid hormones. Nutr Metab (Lond). 2010;7:47.

180. Porter FD, Herman GE. Malformation syndromes caused by disorders of cholesterol synthesis. J Lipid Res. 2011; 52(1):6-34.

181. Hamazaki T, Okuyama H, Ogushi Y, Hama R. Towards a paradigm shift in cholesterol treatment. A re-examination of the cholesterol issue in Japan. Ann Nutr Metab. 2015;66 (Suppl 4):1-116.

182. Weverling-Rijnsburger AW, Blauw GJ, Lagaay AM, Knook DL, Meinders AE, Westendorp RG. Total cholesterol and risk of mortality in the oldest old. Lancet. 1997;350(9085):1119-23.

183. Ravnskov U. High cholesterol may protect against infections and atherosclerosis. QJM. 2003;96(12):927-34.

184. Ravnskov U, McCully KS, Rosch PJ. The statin-low cholesterol-cancer conundrum. QJM. 2012;105(4):383-8.

185. Ravnskov U, de Lorgeril M, Diamond DM, Hama R, Hamazaki T, Hammarskjold B, et al. LDL-C does not cause cardiovascular disease: a comprehensive review of the current literature. Expert Rev Clin Pharmacol. 2018;11(10):959-70.

186. Dzugan SA, Arnold Smith R. Hypercholesterolemia treatment: a new hypothesis or just an accident? Med Hypotheses. 2002;59(6):751-6.

187. Dzugan SA, Rozakis GW, Dzugan KS, Emhof L, Dzugan SS, Xydas C, et al. Correction of steroidopenia as a new method of hypercholesterolemia treatment. Neuro Endocrinol Lett. 2011;32(1):77-81.

188. Arnett DK, Blumenthal RS, Albert MA, Buroker AB, Goldberger ZD, Hahn EJ, et al. 2019 ACC/AHA Guideline on the Primary Prevention of Cardiovascular Disease: A Report of the American College of Cardiology/American Heart Association Task Force on Clinical Practice Guidelines. J Am Coll Cardiol. 2019;74(10):e177-e232.

189. Turner RM, Pirmohamed M. Statin-related myotoxicity: a comprehensive review of pharmacokinetic, pharmacogenomic and muscle components. J Clin Med. 2019;9(1).

190. Gao S, Zhao D, Wang M, Zhao F, Han X, Qi Y, et al. Association between circulating oxidized $L D L$ and atherosclerotic cardiovascular disease: a meta-analysis of observational studies. Can J Cardiol. 2017;33(12):1624-32.

191. Ishigaki Y, Oka Y, Katagiri H. Circulating oxidized LDL: a biomarker and a pathogenic factor. Curr Opin Lipidol. 2009;20(5):363-9.

192. Rhoads JP, Major AS. How oxidized low-density lipoprotein activates inflammatory responses. Crit Rev Immunol. 2018;38(4):333-42.

193. Maroon JC, Bost JW. Omega-3 fatty acids (fish oil) as an anti-inflammatory: an alternative to nonsteroidal antiinflammatory drugs for discogenic pain. Surg Neurol. 2006;65(4):326-31.

194. Pan MH, Lai CS, Ho CT. Anti-inflammatory activity of natural dietary flavonoids. Food Funct. 2010;1(1):15-31.

195. Franceschi C, Campisi J. Chronic inflammation (inflammaging) and its potential contribution to age-associated diseases. J Gerontol A Biol Sci Med Sci. 2014;69(Suppl 1):S4-9.

196. Kouchaki E, Afarini M, Abolhassani J, Mirhosseini N, Bahmani F, Masoud SA, et al. High-dose omega-3 fatty acid plus vitamin D3 supplementation affects clinical symptoms and metabolic status of patients with multiple sclerosis: a randomized controlled clinical trial. J Nutr. 2018;148(8): 1380-6.

197. Turchini GM, Nichols PD, Barrow C, Sinclair AJ. Jumping on the omega-3 bandwagon: distinguishing the role of longchain and short-chain omega-3 fatty acids. Crit Rev Food Sci Nutr. 2012;52(9):795-803.
198. de Groot RHM, Emmett R, Meyer BJ. Non-dietary factors associated with n-3 long-chain PUFA levels in humans - a systematic literature review. $\mathrm{Br} J$ Nutr. 2019;121(7): 793-808.

199. Daley CA, Abbott A, Doyle PS, Nader GA, Larson S. A review of fatty acid profiles and antioxidant content in grass-fed and grain-fed beef. Nutr J. 2010;9:10.

200. Lundebye AK, Lock EJ, Rasinger JD, Nostbakken OJ, Hannisdal R, Karlsbakk E, et al. Lower levels of persistent organic pollutants, metals and the marine omega 3-fatty acid DHA in farmed compared to wild Atlantic salmon (Salmo salar). Environ Res. 2017;155:49-59.

201. Brown AC. Understanding Food: Principles and Preparation. 5th ed: Cengage Learning; 2014. 704 p.

202. Hardy C, Gallagher M. Strong medicine, how to conquer chronic disease and achieve your full genetic potential. Dragon Door Publications, Inc; 2015. p. 604.

203. Boran G, Karaçam H, Boran M. Changes in the quality of fish oils due to storage temperature and time. Food Chemistry. 2006;98(4):693-8.

204. De Alzaa F, Guillaume C, Ravetti L. Evaluation of chemical and physical changes in different commercial oils during heating. Acta Sci Nutr Health. 2018;2(6):2-11.

205. Halvorsen BL, Blomhoff R. Determination of lipid oxidation products in vegetable oils and marine omega-3 supplements. Food Nutr Res. 2011;55.

206. Yun JM, Surh J. Fatty acid composition as a predictor for the oxidation stability of korean vegetable oils with or without induced oxidative stress. Prev Nutr Food Sci. 2012;17(2): $158-65$.

207. Azizian H, Kramer JK. A rapid method for the quantification of fatty acids in fats and oils with emphasis on trans fatty acids using Fourier Transform near infrared spectroscopy (FT-NIR). Lipids. 2005;40(8):855-67.

208. Aladedunye FA, Przybylski R. Degradation and nutritional quality changes of oil during frying. J Am Oil Chem' Soc. 2009;86(2):149-56.

209. Dhaka V, Gulia N, Ahlawat KS, Khatkar BS. Trans fatssources, health risks and alternative approach - A review. J Food Sci Technol. 2011;48(5):534-41.

210. Mozaffarian D, Longstreth WT, Jr, Lemaitre RN, Manolio TA, Kuller LH, Burke GL, et al. Fish consumption and stroke risk in elderly individuals: the cardiovascular health study. Arch Intern Med. 2005;165(2):200-6.

211. Mozaffarian D, Gottdiener JS, Siscovick DS. Intake of tuna or other broiled or baked fish versus fried fish and cardiac structure, function, and hemodynamics. Am J Cardiol. 2006;97(2):216-22.

212. Yurko-Mauro K, Kralovec J, Bailey-Hall E, Smeberg V, Stark JG, Salem N, Jr. Similar eicosapentaenoic acid and docosahexaenoic acid plasma levels achieved with fish oil or krill oil in a randomized double-blind four-week bioavailability study. Lipids Health Dis. 2015;14:99.

213. Browning LM, Walker CG, Mander AP, West AL, Madden J, Gambell JM, et al. Incorporation of eicosapentaenoic and docosahexaenoic acids into lipid pools when given as supplements providing doses equivalent to typical intakes of oily fish. Am J Clin Nutr. 2012;96(4):748-58.

214. Harris WS. The Omega-6:Omega-3 ratio: A critical appraisal and possible successor. Prostaglandins Leukot Essent Fatty Acids. 2018;132:34-40.

215. Delgado GE, Marz W, Lorkowski S, von Schacky C, Kleber ME. Omega- 6 fatty acids: Opposing associations with riskThe Ludwigshafen Risk and Cardiovascular Health Study. J Clin Lipidol. 2017;11(4):1082-90 e14. 
216. Igarashi M, Ma K, Chang L, Bell JM, Rapoport SI. Dietary n-3 PUFA deprivation for 15 weeks upregulates elongase and desaturase expression in rat liver but not brain. J Lipid Res. 2007;48(11):2463-70.

217. Horas HNS, Nishiumi S, Kawano Y, Kobayashi T, Yoshida M, Azuma T. Adrenic acid as an inflammation enhancer in nonalcoholic fatty liver disease. Arch Biochem Biophys. 2017;623-624:64-75.

218. Harris WS, Von Schacky C. The Omega-3 Index: a new risk factor for death from coronary heart disease? Prev Med 2004;39(1):212-20.

219. De Meester F, WR R, Zibadi S. Omega-6/3 Fatty Acids: Functions, Sustainability Strategies and Perspectives. Humana; 2012.

220. Datta S. Fish as a source of antioxidants. In: Das RC, Sinha A, Pal AK, Datta S, Sardar P, editors. Nutritional and biochemical techniques in fisheries. (1st ed). Director, CIFE; 2003.

221. Osterud B, Elvevoll EO. Dietary omega-3 fatty acids and risk of type 2 diabetes: lack of antioxidants? Am J Clin Nutr. 2011;94(2):617-8; author reply 8-9.

222. Tulleken JE, Limburg PC, Muskiet FA, van Rijswijk MH. Vitamin E status during dietary fish oil supplementation in rheumatoid arthritis. Arthritis Rheum. 1990;33(9):1416-9.

223. Narayanankutty A, Kottekkat A, Mathew SE, Illam SP, Suseela IM, Raghavamenon AC. Vitamin E supplementation modulates the biological effects of omega-3 fatty acids in naturally aged rats. Toxicol Mech Methods. 2017;27(3):207-14.

224. Brown JE, Wahle KW. Effect of fish-oil and vitamin E supplementation on lipid peroxidation and whole-blood aggregation in man. Clin Chim Acta. 1990;193(3):147-56

225. Ambati RR, Phang SM, Ravi S, Aswathanarayana RG. Astaxanthin: sources, extraction, stability, biological activities and its commercial applications-a review. Mar Drugs. 2014;12(1):128-52.

226. Saw CL, Yang AY, Guo Y, Kong AN. Astaxanthin and omega-3 fatty acids individually and in combination protect against oxidative stress via the Nrf2-ARE pathway. Food Chem Toxicol. 2013;62:869-75.

227. Foran SE, Flood JG, Lewandrowski KB. Measurement of mercury levels in concentrated over-the-counter fish oil preparations: is fish oil healthier than fish? Arch Pathol Lab Med. 2003;127(12):1603-5.

228. O'Connor A. What's in Your Fish Oil Supplements?. New Yorg Times; 2014.

229. ConsumerLab. Is fish oil safe? Is it contaminated with mercury and PCBs? 2012. Available from: https://www. consumerlab.com/answers/is-fish-oil-safe/fish-oil_ contamination/

230. Elagizi A, Lavie CJ, Marshall K, DiNicolantonio JJ, O'Keefe JH, Milani RV. Omega-3 Polyunsaturated Fatty Acids and Cardiovascular Health: A Comprehensive Review. Prog Cardiovasc Dis. 2018;61(1):76-85.

231. Cameron-Smith D, Albert BB, Cutfield WS. Fishing for answers: is oxidation of fish oil supplements a problem? J Nutr Sci. 2015;4:e36.

232. Begtrup KM, Krag AE, Hvas AM. No impact of fish oil supplements on bleeding risk: a systematic review. Dan Med J. 2017;64(5).

233. Leaf A, Jorgensen MB, Jacobs AK, Cote G, Schoenfeld DA, Scheer J, et al. Do fish oils prevent restenosis after coronary angioplasty? Circulation 1994;90(5):2248-57.

234. Bouwens $M$, van de Rest O, Dellschaft N, Bromhaar MG, de Groot LC, Geleijnse JM, et al. Fish-oil supplementation induces antiinflammatory gene expression profiles in human blood mononuclear cells. Am J Clin Nutr. 2009;90(2):415-24.
235. Beckermann B, Beneke M, Seitz I. Comparative bioavailability of eicosapentaenoic acid and docasahexaenoic acid from triglycerides, free fatty acids and ethyl esters in volunteers. Arzneimittelforschung. 1990;40(6): $700-4$.

236. Neubronner J, Schuchardt JP, Kressel G, Merkel M, von Schacky C, Hahn A. Enhanced increase of omega-3 index in response to long-term n-3 fatty acid supplementation from triacylglycerides versus ethyl esters. Eur J Clin Nutr. 2011;65(2):247-54.

237. Römpp Lexikon Chemie - Römpp Online. Georg Thieme Verlag; 2019.

238. Bruchhausen F, Dannhardt G. Hagers Handbuch der Pharmazeutischen Praxis. Springer-Verlag; 2013.

239. Liau KM, Lee YY, Chen CK, Rasool AH. An open-label pilot study to assess the efficacy and safety of virgin coconut oil in reducing visceral adiposity. ISRN Pharmacol. 2011;2011: 949686.

240. Beare-Rogers JL, Dieffenbacher A, Holm JV. Lexicon of lipid nutrition (IUPAC Technical Report). Pure Appl Chem. 2001;73 (4):685-744.

241. Kiralan M, Gül V, Metin Kara S. Fatty acid composition of hempseed oils from different locations in Turkey. Span J Agric Res. 2010;8(2):385-90.

242. Tardy A-L, Morio B, Chardigny J-M, Malpuech-Brugère C. Ruminant and industrial sources of trans-fat and cardiovascular and diabetic diseases. Nutrition Research Reviews. 2011;24(1):111-7

243. Bhardwaj S, Passi SJ, Misra A. Overview of trans fatty acids: biochemistry and health effects. Diabetes Metab Syndr. 2011;5(3):161-4.

244. Kolderup A, Svihus B. Fructose metabolism and relation to atherosclerosis, type 2 diabetes, and obesity. J Nutr Metab. 2015;2015:823081.

245. Jheng HF, Tsai PJ, Guo SM, Kuo LH, Chang CS, Su IJ, et al. Mitochondrial fission contributes to mitochondrial dysfunction and insulin resistance in skeletal muscle. Mol Cell Biol. 2012;32(2):309-19.

246. Vitale G, Salvioli S, Franceschi C. Oxidative stress and the ageing endocrine system. Nat Rev Endocrinol. 2013;9(4) 228-40.

247. Esser N, Legrand-Poels S, Piette J, Scheen AJ, Paquot N Inflammation as a link between obesity, metabolic syndrome and type 2 diabetes. Diabetes Res Clin Pract. 2014;105(2): $141-50$

248. Osborn O, Olefsky JM. The cellular and signaling networks linking the immune system and metabolism in disease. Nat Med. 2012;18(3):363-74

249. Kadowaki T, Yamauchi T, Kubota N, Hara K, Ueki K, Tobe K. Adiponectin and adiponectin receptors in insulin resistance, diabetes, and the metabolic syndrome. J Clin Invest. 2006;116(7):1784-92.

250. Uzunlulu M, Telci Caklili O, Oguz A. Association between Metabolic Syndrome and Cancer. Ann Nutr Metab. 2016; 68(3):173-9.

251. McCracken E, Monaghan M, Sreenivasan S. Pathophysiology of the metabolic syndrome. Clin Dermatol. 2018;36(1): $14-20$.

252. Jha SK, Jha NK, Kumar D, Ambasta RK, Kumar P. Linking mitochondrial dysfunction, metabolic syndrome and stress signaling in Neurodegeneration. Biochim Biophys Acta Mol Basis Dis. 2017;1863(5):1132-46.

253. Serhan CN, Chiang N. Endogenous pro-resolving and antiinflammatory lipid mediators: a new pharmacologic genus. Br J Pharmacol. 2008;153(Suppl 1):S200-15. 
254. Yashodhara BM, Umakanth S, Pappachan JM, Bhat SK, Kamath R, Choo BH. Omega-3 fatty acids: a comprehensive review of their role in health and disease. Postgrad Med J. 2009;85(1000):84-90.

255. Knab LM, Grippo PJ, Bentrem DJ. Involvement of eicosanoids in the pathogenesis of pancreatic cancer: the roles of cyclooxygenase-2 and 5-lipoxygenase. World J Gastroenterol. 2014;20(31):10729-39.

256. Abdolmaleki F, Kovanen PT, Mardani R, Gheibi-Hayat SM, Bo S, Sahebkar A. Resolvins: emerging players in autoimmune and inflammatory diseases. Clin Rev Allergy Immunol. 2019.

257. Burhani MD, Rasenick MM. Fish oil and depression: The skinny on fats. J Integr Neurosci. 2017;16(s1):S115-S24.

258. Gao H, Geng T, Huang T, Zhao Q. Fish oil supplementation and insulin sensitivity: a systematic review and metaanalysis. Lipids Health Dis. 2017;16(1):131.

259. Gioxari A, Kaliora AC, Marantidou F, Panagiotakos DP. Intake of omega-3 polyunsaturated fatty acids in patients with rheumatoid arthritis: A systematic review and meta-analysis. Nutrition. 2018:45:114-24 e4.

260. Grimm MOW, Michaelson DM, Hartmann T. Omega-3 fatty acids, lipids, and apoE lipidation in Alzheimer's disease: a rationale for multi-nutrient dementia prevention. J Lipid Res. 2017;58(11):2083-101.

261. Healy-Stoffel M, Levant B. N-3 (omega-3) fatty acids: effects on brain dopamine systems and potential role in the etiology and treatment of neuropsychiatric disorders. CNS Neurol Disord Drug Targets. 2018;17(3):216-32.

262. Jing K, Wu T, Lim K. Omega-3 polyunsaturated fatty acids and cancer. Anticancer Agents Med Chem. 2013; 13(8):1162-77.

263. Kumar A, Mastana SS, Lindley MR. n-3 Fatty acids and asthma. Nutr Res Rev. 2016;29(1):1-16.

264. Miyata J, Arita M. Role of omega-3 fatty acids and their metabolites in asthma and allergic diseases. Allergol Int. 2015;64(1):27-34.

265. Mozaffari H, Daneshzad E, Larijani B, Bellissimo N, Azadbakht L. Dietary intake of fish, n-3 polyunsaturated fatty acids, and risk of inflammatory bowel disease: a systematic review and meta-analysis of observational studies. Eur $J$ Nutr. 2019.

266. Simopoulos AP. Omega-3 fatty acids in inflammation and autoimmune diseases. J Am Coll Nutr. 2002;21(6):495-505.

267. Simopoulos AP. An Increase in the Omega-6/Omega-3 Fatty Acid Ratio Increases the Risk for Obesity. Nutrients. 2016; 8(3):128.

268. Siriwardhana N, Kalupahana NS, Moustaid-Moussa N. Health benefits of $n-3$ polyunsaturated fatty acids: eicosapentaenoic acid and docosahexaenoic acid. Adv Food Nutr Res. 2012;65:211-22.

269. Soveyd N, Abdolahi M, Bitarafan S, Tafakhori A, Sarraf P, Togha $M$, et al. Molecular mechanisms of omega-3 fatty acids in the migraine headache. Iran $J$ Neurol. 2017;16(4): 210-7.

270. Swanson D, Block R, Mousa SA. Omega-3 fatty acids EPA and DHA: health benefits throughout life. Adv Nutr. 2012; 3(1):1-7.

271. Willemsen LEM. Dietary $n-3$ long chain polyunsaturated fatty acids in allergy prevention and asthma treatment. Eur J Pharmacol. 2016;785:174-86.

272. He XX, Wu XL, Chen RP, Chen C, Liu XG, Wu BJ, et al. Effectiveness of omega- 3 polyunsaturated fatty acids in non-alcoholic fatty liver disease: a meta-analysis of randomized controlled trials. PLoS One. 2016;11(10):e0162368.

273. Reese I, Werfel T. Do long-chain omega-3 fatty acids protect from atopic dermatitis? J Dtsch Dermatol Ges 2015;13(9): 879-85.

\section{History}

Received September 9, 2020

Accepted April 26, 2021

Published online May 27, 2021

\section{Acknowledgement}

The author would like to thank Gilian Crowther for carefully proofreading the manuscript.

\section{Conflict of interest}

RW works at a company that sells fish oil and other nutritional supplements.

\section{Note regarding previous publication}

This article was published in German in similar form in the journal "OM \& Ernährung: Fachzeitschrift für Orthomolekulare Medizin" as a two-part article (No. 169 \& 179). The article is only available as a hardcopy and not available online. The journal was informed upon initial submission that a later publication of this article in a PubMed-listed, peer-reviewed, international journal was planned. Significant modifications/improvements and updates were made for the English version throughout the text, including the addition of 66 new references, the addition of an introduction, a rewritten abstract and an expanded conclusion.

\section{ORCID}

Reinhard Waehler

(D)https://orcid.org/0000-0003-1634-3377

\section{Dr. Reinhard Waehler}

TISSO Naturprodukte GmbH

Eisenstraße 1

57482 Wenden

Germany

dr.waehler@tisso.de 